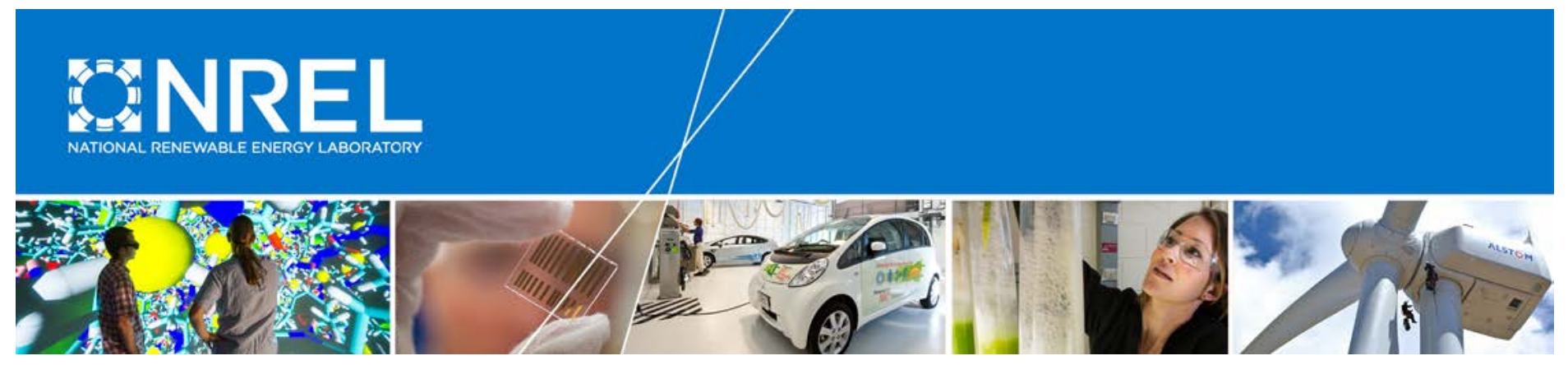

\title{
Timescales of Energy Storage Needed for Reducing Renewable Energy Curtailment
}

Paul Denholm and Trieu Mai National Renewable Energy Laboratory

NREL is a national laboratory of the U.S. Department of Energy Office of Energy Efficiency \& Renewable Energy Operated by the Alliance for Sustainable Energy, LLC

This report is available at no cost from the National Renewable Energy Laboratory (NREL) at www.nrel.gov/publications.

Technical Report

NREL/TP-6A20-68960

September 2017 


\title{
Timescales of Energy Storage Needed for Reducing Renewable Energy Curtailment
}

\author{
Paul Denholm and Trieu Mai \\ National Renewable Energy Laboratory
}

Prepared under Task No. WEPG.10348.05.01.04

NREL is a national laboratory of the U.S. Department of Energy Office of Energy Efficiency \& Renewable Energy Operated by the Alliance for Sustainable Energy, LLC

This report is available at no cost from the National Renewable Energy Laboratory (NREL) at www.nrel.gov/publications.

National Renewable Energy Laboratory 15013 Denver West Parkway Golden, CO 80401

303-275-3000 • www.nrel.gov

\section{Technical Report}

NREL/TP-6A20-68960

September 2017

Contract No. DE-AC36-08G028308 


\section{NOTICE}

This report was prepared as an account of work sponsored by an agency of the United States government. Neither the United States government nor any agency thereof, nor any of their employees, makes any warranty, express or implied, or assumes any legal liability or responsibility for the accuracy, completeness, or usefulness of any information, apparatus, product, or process disclosed, or represents that its use would not infringe privately owned rights. Reference herein to any specific commercial product, process, or service by trade name, trademark, manufacturer, or otherwise does not necessarily constitute or imply its endorsement, recommendation, or favoring by the United States government or any agency thereof. The views and opinions of authors expressed herein do not necessarily state or reflect those of the United States government or any agency thereof.

This report is available at no cost from the National Renewable Energy Laboratory (NREL) at www.nrel.gov/publications.

Available electronically at SciTech Connect http:/www.osti.gov/scitech

Available for a processing fee to U.S. Department of Energy and its contractors, in paper, from:

U.S. Department of Energy

Office of Scientific and Technical Information

P.O. Box 62

Oak Ridge, TN 37831-0062

OSTI http://www.osti.gov

Phone: 865.576.8401

Fax: 865.576.5728

Email: reports@osti.gov

Available for sale to the public, in paper, from:

U.S. Department of Commerce

National Technical Information Service

5301 Shawnee Road

Alexandria, VA 22312

NTIS http://www.ntis.gov

Phone: 800.553 .6847 or 703.605 .6000

Fax: 703.605.6900

Email: orders@ntis.gov 


\section{Acknowledgments}

Anthony Lopez and Galen Maclaurin generated the wind resource data used in this analysis. Assistance in generating and processing solar data was provided by Bethany Frew and Janine Freeman. Wesley Cole, Thomas Jenkin, Eric Lantz, and David Mooney provided useful discussions and comments. Editing and graphics support was provided by Al Hicks, Mary Lukkonen, and Mike Meshek. The authors would also like to thank Patrick Gilman (DOE), Adam Goss (ClearPath Foundation), and Rich Tusing (Allegheny Science and Technology, and Senior Advisor to the DOE Wind Energy Technology Office) for their reviews and comments during the analysis and publication process.

Finally, we gratefully acknowledge funding for this work from the U.S. Department of Energy's Office of Energy Efficiency and Renewable Energy under contract number DE-AC36$08 \mathrm{GO} 28308$. 


\section{List of Acronyms}

$\mathrm{AC}$

CAES

$\mathrm{CO}_{2}$

CSP

EIA

ERCOT

GW

ISO

$\mathrm{kW}$

$\mathrm{kWh}$

MW

MWh

NREL

O\&M

PV

ReEDS

REFlex

T\&D

VG alternating current

compressed air energy storage

carbon dioxide

concentrating solar power

U.S. Energy Information Administration

Electricity Reliability Council of Texas

gigawatt

Independent System Operator

kilowatt

kilowatt-hour

megawatt

megawatt-hour

National Renewable Energy Laboratory

operations and maintenance

photovoltaic

Regional Energy Deployment System

Renewable Energy Flexibility

transmission and distribution

variable generation 


\section{Executive Summary}

Integrating large amounts of variable generation (VG) wind and solar into a region's power grid without causing significant VG curtailment - and thus preserving VG's environmental and economic value - will likely require increasing system flexibility through a combination of changes to grid operation and deployment of enabling technologies. Interest in energy storage as an enabling technology has increased as the actual and projected prices of storage have declined. Yet questions remain about the amount and configuration of storage needed to reduce VG curtailment as well as how to value the multiple benefits storage can offer VG integration and grid operations.

Energy storage size is defined by power capacity (the charge/discharge rate, typically measured in kilowatts or megawatts) and energy capacity (the amount of stored energy, typically measured in kilowatt-hours or megawatt-hours). Linking these two metrics is storage duration: the amount of time the storage can discharge at its power capacity before depleting its energy capacity. For example, a battery with $1 \mathrm{MW}$ of power capacity and $4 \mathrm{MWh}$ of usable energy capacity has a duration of 4 hours.

This report analyzes the storage duration required to reduce VG curtailment under high-VG scenarios. It also examines the value of storage with varying durations. This initial valuation approach can provide insight into the optimal storage sizing from the perspective of a storage developer. Note that this report's focus on energy storage does not imply that storage is required to integrate VG at penetrations up to $55 \%$, which is the level contemplated in this analysis. Multiple options for integrating VG are available, and the effectiveness of these options should be evaluated with and without the use of storage.

Our scenarios are based on the U.S. Department of Energy's (DOE's) Wind Vision study, which examined the potential for wind to provide a large fraction of the nation's electricity supply. Our case study examines a scenario where VG provides $55 \%$ of the electricity demand in the largely isolated Electricity Reliability Council of Texas (ERCOT) grid system in 2050. In 2016, ERCOT met about $15 \%$ of its annual electricity demand with wind. We evaluate three primary scenarios of $55 \% \mathrm{VG}$ :

- Wind Vision: $44 \%$ wind, $11 \%$ photovoltaics (PV)

- Minimum curtailment: $37 \%$ wind, $18 \% \mathrm{PV}$

- Equal mix: $27.5 \%$ wind, $27.5 \%$ PV.

We use the National Renewable Energy Laboratory's (NREL's) Renewable Energy Flexibility (REFlex) model to dispatch the power system under each scenario and analyze the use of energy storage to avoid curtailment. We assume that new transmission construction avoids significant transmission-related curtailment, so all curtailment results from system-generation constraints (e.g., minimum turndown ratios or must-run capacity).

Figure ES-1 shows how curtailment can be reduced by adding storage. Across our three scenarios, at $55 \% \mathrm{VG}$, between $11 \%$ and $16 \%$ of VG energy is curtailed without storage (the points with zero storage in the figures). Among our primary scenarios, the highest curtailment amount occurred with an equal mix of wind and PV. For context, total curtailment of wind in 
2016 in ERCOT was about 2\% (mostly due to transmission constraints). Figure ES-1a shows the case where we add storage capacity with 4 hours of duration. Figure ES-1b shows the case where we fixed storage capacity at $8.5 \mathrm{GW}$ of storage power capacity (equivalent to about one-third of ERCOT's projected peaking capacity in $2050^{1}$ ) but vary duration. The case with $8.5 \mathrm{GW}$ of capacity with 4 hours of duration reduced total curtailment by $24 \%-38 \%$ (resulting in a total VG curtailment rate between $8 \%$ and $10 \%$ ).

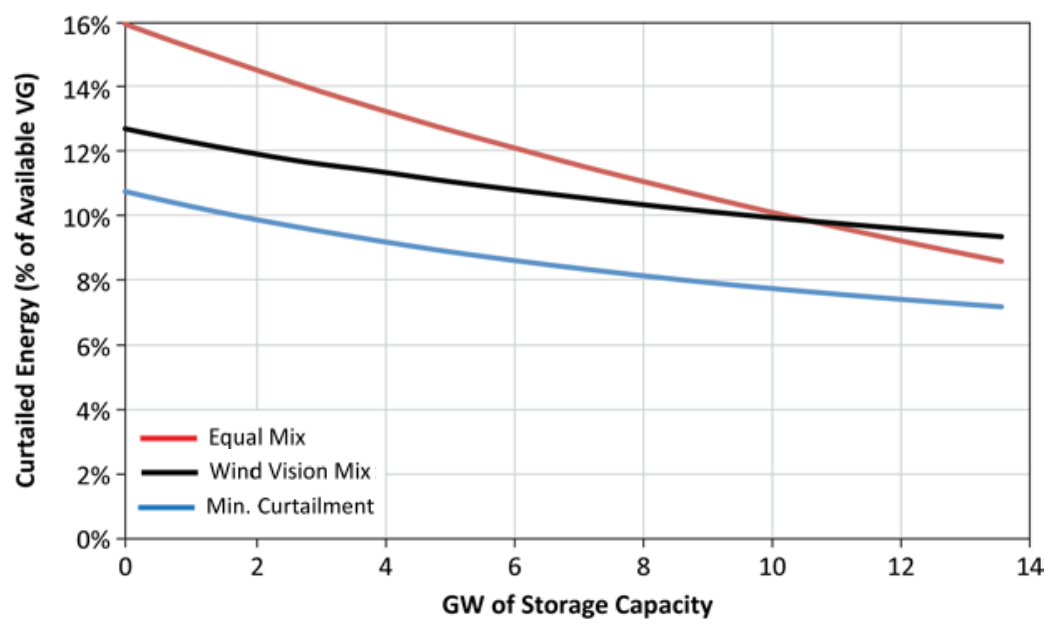

a) Fixed storage duration (4 hours)

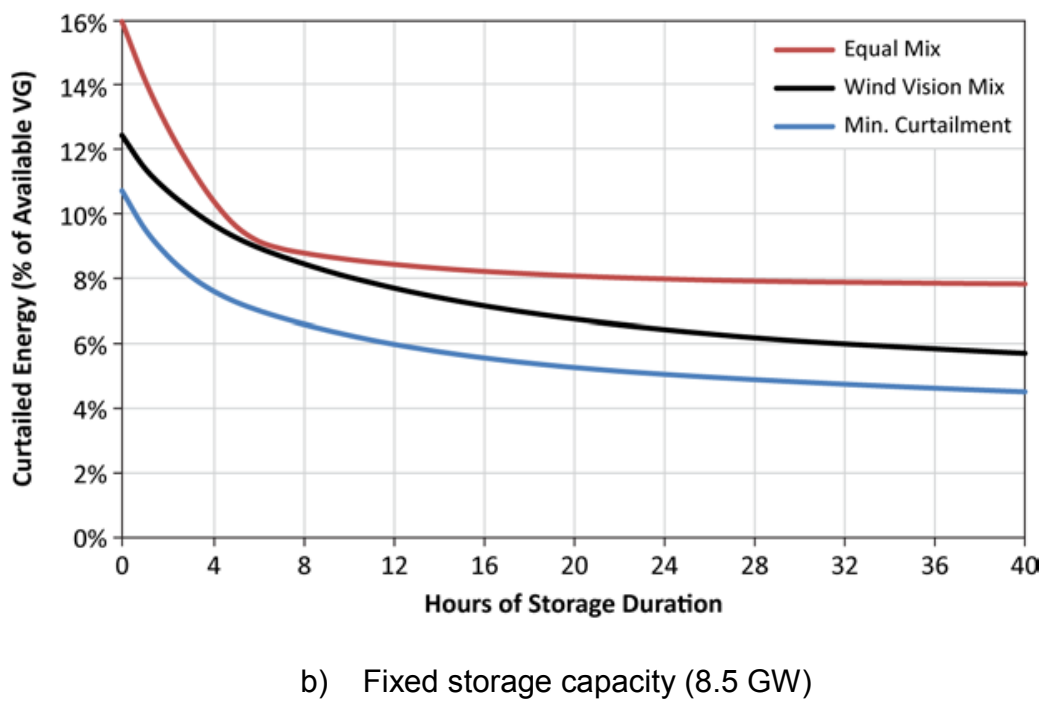

Figure ES-1. Total curtailment as a function of storage power capacity (a) and duration (b) at a fixed $55 \%$ VG penetration

Figure ES-1b shows that adding additional storage duration further reduces curtailment but with diminishing returns. For example, storage with 4 hours of duration in the Wind Vision scenario avoids $35 \%$ of the curtailment that could be avoided with an 8.5 -GW storage device of unlimited

\footnotetext{
${ }^{1}$ This value $(8.5 \mathrm{GW})$ was based on the amount of storage in the Wind Vision study by 2050 . The comparison to ERCOT's peaking capacity is based on U.S. Energy Information Administration (EIA) projections of peaking capacity in 2050 (28 GW), growing from about $20 \mathrm{GW}$ in 2016 (EIA 2017a).
} 
duration and about $70 \%$ in the equal-mix scenario. An 8-hour duration storage device would reduce $49 \%$ and $88 \%$ of curtailment (relative to an unlimited duration device) in the Wind Vision and equal-mix scenarios, respectively. Increasing duration beyond these levels, the incremental amount of avoided curtailment falls off rapidly, especially in the cases with greater amounts of $\mathrm{PV}$. Completely eliminating curtailment is probably not practical as it would require a significant increase in storage power capacity as well as very long durations.

These results indicate the avoided-curtailment benefits of adding storage with relatively short durations, but they do not consider energy storage's other sources of value. In fact, capacity value - the ability of storage to replace conventional peaking capacity — can be a large source of value. Currently, several U.S. markets award full capacity credit to devices with 4 hours of capacity, which further decreases the need for longer duration storage (at least under current market rules).

Overall, our results suggest that relatively short-duration energy storage might offer an effective path to reduce VG curtailments at penetrations up to 55\%. Across all the mixes of wind and solar resources analyzed, at least half of the potential avoided-curtailment benefits are realized with 8 hours of storage, and the first 4 hours provide the largest benefit. At VG penetrations up to $55 \%$, there appears to be little incremental benefit in deploying very-long-duration or seasonal storage. 


\section{Table of Contents}

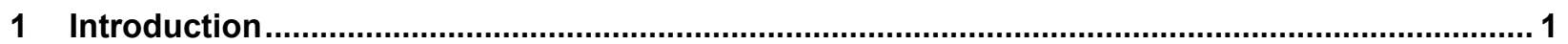

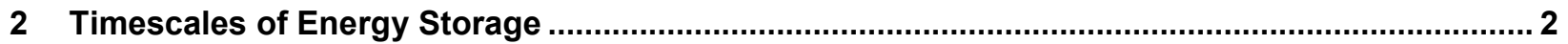

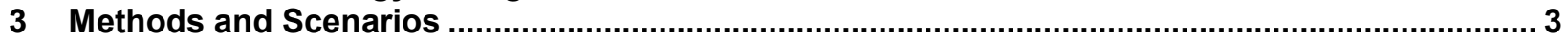

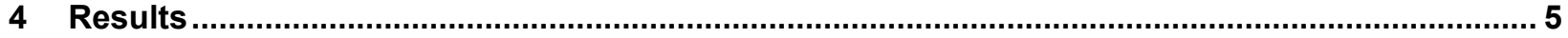

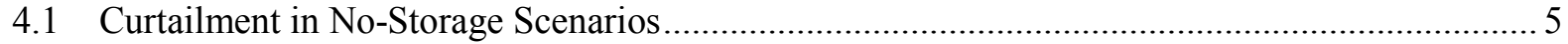

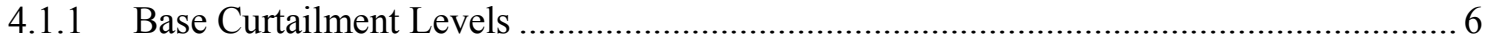

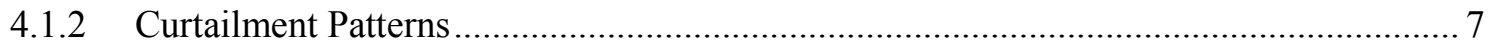

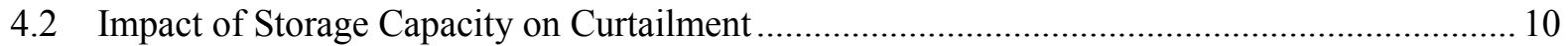

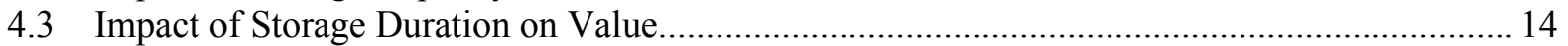

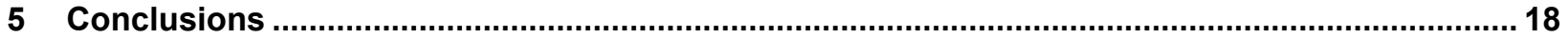

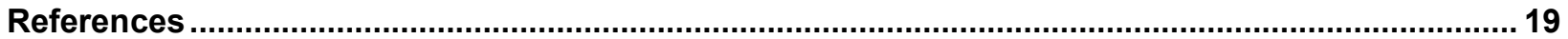

Appendix 


\section{List of Figures}

Figure ES-1. Total curtailment as a function of storage power capacity (a) and duration (b) at a fixed 55\%

VG penetration................................................................................................................. vi

Figure 1. Actual load, wind, and average price conditions in ERCOT on March 22-23, 2016 ................ 5

Figure 2. Total VG curtailment rate (a) and energy curtailed (b) under increasing VG penetrations, with different mixes of wind and solar and no energy storage ................................................... 6

Figure 3. Total VG curtailed at an annual VG penetration of $55 \%$ as a function of wind/solar mix, with no energy storage

Figure 4. Simulated curtailment during January 20-21 in ERCOT with no storage using 2012 wind, solar,

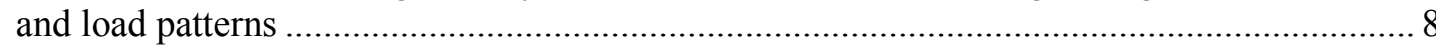

Figure 5. Duration curve of curtailment at 55\% VG in ERCOT with no storage using 2012 wind, solar,

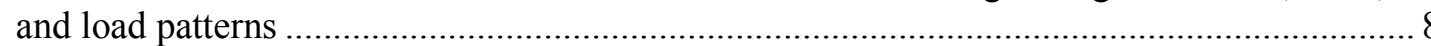

Figure 6. Distributions of duration (a) and energy (b) of curtailment events with no storage using 2012

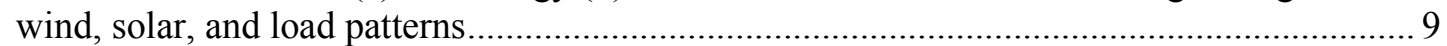

Figure 7. Total curtailment (a) and curtailment rate (b) at 55\% VG as a function of storage power capacity for the three study scenarios at varying storage durations

Figure 8 . Avoided curtailment at $55 \% \mathrm{VG}$ as a function of storage power capacity for the equal-mix and Wind Vision scenarios with varying amounts of additional storage duration ....................... 12

Figure 9. Total curtailment (a) and avoided curtailment (b) at $55 \% \mathrm{VG}$ as a function of storage duration assuming $8.5 \mathrm{GW}$ of storage power capacity for the three study scenarios......................... 13

Figure 10. Capacity credit and annualized capacity value of storage as a function of hours of storage

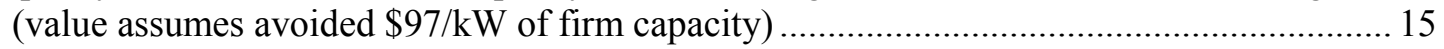

Figure 11. Energy value of energy storage under different cases ......................................................... 16

Figure 12. Total value of storage as a function of storage duration......................................................... 16

Figure 13. Incremental value of energy storage, medium-value case .................................................... 17

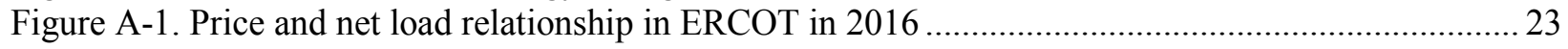

\section{List of Tables}

Table 1. Cases Evaluated.... 


\section{Introduction}

Integrating large amounts of variable generation (VG) wind and solar into a region's power grid is challenging because of the mismatch of electricity supply and demand across various timescales. A number of grid-integration studies have been performed in the United States with differing levels of VG penetration and modeling fidelity. A key finding of these studies is the potentially significant increase in renewable energy curtailment that occurs at increasing penetration. This increase in curtailment can substantially reduce the value of VG and decrease its cost-competitiveness.

Studies examining energy penetrations of up to about 33\% (Lew et al. 2013; Bloom et al. 2016) have found that well-understood changes to grid operation - including greater regional cooperation, demand response, and increased conventional generator flexibility - can lead to economic integration without the need for significant new deployment of "enabling" technologies such as energy storage or large amounts of curtailment (Cochran et al. 2015). Beyond 33\%, it becomes even more important to exploit spatial diversity to minimize curtailment and consider the impact of different VG mixes to exploit their varying temporal characteristics (Brinkman 2015; Brinkman et al. 2016; MacDonald et al. 2016; Mai et al. 2014).

Few integration and planning studies of high VG deployment have considered large-scale storage deployment in detail (examining storage size and configuration needed to minimize curtailment), typically because historical storage price projections preclude the economic use of storage compared with more cost-effective flexibility options.

The significant reduction in costs for energy storage observed recently and projected going forward (Nykvist and Nilsson 2015) warrants further examination of increased storage deployment in high-VG scenarios. Greater storage deployment may "naturally" occur (independent of renewable deployment) as storage becomes cost-competitive with conventional peaking resources (Denholm et al. 2015). Storage deployment might also increase as greater renewable deployment increases the value of storage (Eichman et al. 2015).

The U.S. Department of Energy's (DOE's) Wind Vision study provides a number of scenarios that enable detailed examination of the potential role of energy storage at increased penetration of VG (DOE 2015; Lantz et al. 2016). The study examines a nationwide penetration (on an annual energy basis) of 35\% wind (and 10\% solar) by 2050 . However, the penetration varies regionally, with a $44 \%$ annual contribution from wind, along with $11 \%$ from solar, in the Electric Reliability Council of Texas (ERCOT) grid. The Wind Vision study assumes a relatively modest increase in transmission capacity between ERCOT and the rest of the United States. As a result, the study provides scenarios with VG contributions well over $50 \%$, creating a useful test for the role of storage in mitigating curtailment in relatively isolated regions.

A key element of increasing energy storage use to integrate renewable energy and reduce curtailment is identifying the timescales of storage needed - that is, the duration of energy storage capacity per unit of power capacity. This can also be expressed as the energy-to-power ratio. The duration requirement is related to the patterns of energy demand and renewable supply. 
This report analyzes the storage duration required to reduce VG curtailment under high-VG scenarios. It also examines the value of storage with varying durations and how these insights might be used to optimize storage sizing from the perspective of a storage developer. Section 2 briefly discusses the timescales of different energy storage technologies and their potential application in integrating renewable energy. Section 3 describes our methods. Section 4 shows our results, including the impact of storage duration on curtailment and value. Section 5 concludes and suggests areas for future work.

\section{Timescales of Energy Storage}

An energy storage device's size is defined by its power capacity and energy capacity. The power capacity reflects the rate at which the device can charge or discharge. Power capacity for energy storage is typically measured in kilowatts or megawatts, just as it is for conventional power plants. The energy capacity reflects the amount of stored energy, typically measured in kilowatthours or megawatt-hours. Linking these two metrics is storage duration: the amount of time the storage can discharge at its power capacity before depleting its energy capacity. For example, a battery with $1 \mathrm{MW}$ of power capacity and $4 \mathrm{MWh}$ of usable energy capacity has a duration of 4 hours. Although this is a fairly straightforward measure, actual energy capacity ratings are complicated by limits on how the storage device can be used economically. For example, only a fraction of the rated energy capacity may actually be used to avoid degrading battery performance over its life (Peterson, Apt, and Whitacre 2010). For this analysis, we base power capacity on the devices' alternating current (AC) ratings, and we base energy capacity on the devices' economically usable discharge capacity at their AC power ratings.

The power and energy capacities of an energy storage device determine the applications for which the device is useful. These applications are often categorized by the timescale or duration of discharge needed for a particular grid service. Timescales of storage technologies that have been deployed at significant scale range from fractions of a second to many hours (DOE 2017). Several timescales have been identified for integrating renewable energy.

At the shortest timescale (seconds to minutes), significant storage has been deployed for providing operating reserves including frequency regulation, which responds to small random variations in normal demand (Xu et al. 2016). Although individual renewable generators can demonstrate rapid, short-term fluctuations in output (e.g., from clouds passing over photovoltaics [PV] systems), grid-integration studies have found little inherent need for storage to address these problems, largely because diverse renewable generator locations minimize rapid fluctuations of aggregate renewable output (Mills and Wiser 2010; Tabone, Goebel, and Callaway 2016). The ultimate market potential for storage providing operating reserves is limited by the relatively small market size (Zhou, Levin, and Conzelmann 2016) and competition from other resources, such as demand response and curtailed renewable energy (Ma et al. 2014). ${ }^{2}$

At longer timescales (up to several hours), storage has been deployed to provide peaking capacity and to shift energy from off-peak to peak periods. Such storage can enable thermal

\footnotetext{
${ }^{2}$ The technical potential for energy storage providing operating reserves in ERCOT is about 1,900 MW, consisting of 1,400 MW of responsive reserves (out of a 2,800-MW total requirement, of which half is already provided by demand response) and $500 \mathrm{MW}$ of regulation reserves (Zhou et al. 2016).
} 
power plants to run at full output or avoid shutdown, thus increasing utilization. ${ }^{3}$ Historically, this category is dominated by pumped hydro storage, with smaller contributions from compressed air energy storage (CAES), and thermal energy storage in concentrating solar power (CSP) plants (DOE 2017). Batteries are an emerging technology for providing peak power (Cardwell and Krauss 2017). For renewable integration, several hours of storage can be used to address ramp events and curtailment that results from the daily mismatch of renewable supply and electricity demand.

At an even longer timescale, storage could provide capacity greater than that needed for daily shifting, or greater than about 10 hours. Some pumped hydro plants (and proposed CAES plants) have capacities somewhat larger than 10 hours, which enables the plants to perform daily shifting and provide additional arbitrage between weekday and weekend price differences (DOE 2014). Various fuel production and storage technologies have been proposed to provide capacity beyond a day or so, including hydrogen and methane (power to gas) (Götz et al. 2016). These technologies could potentially address the seasonal mismatch of supply and demand associated with renewable generation. Seasonal mismatches are largely driven by high wind and solar conditions in the spring, which is the period of lowest electricity demand. Seasonal storage has been proposed as potentially important in scenarios that have renewables providing $100 \%$ or close to $100 \%$ of a system's electricity demand (Blanco and Faaij 2018).

\section{Methods and Scenarios}

This section discusses our methods for evaluating the duration and value of energy storage used for reducing VG curtailment, including our study scenarios and the parameters we use to calculate the capacity and energy values of energy storage.

To understand the impact of storage duration on renewable energy integration and curtailment, we perform chronological simulations using NREL's Renewable Energy Flexibility (REFlex) model (Denholm and Hand 2011). REFlex performs a chronological dispatch of aggregated thermal and hydro units assuming generator flexibility limits, including ramp rates and minimum generation levels. It also performs chronological dispatch of energy storage. The model is used to dispatch the power system with increasing levels of wind and solar to examine resulting curtailment patterns and the ability to avoid curtailment via energy storage.

Simulations are performed using 6 years of historical load patterns and corresponding (simulated) wind and solar generation data (2007-2012). Hourly load data are from ERCOT (ERCOT 2017a). The Wind Vision study examines deployment of wind and solar out to the year 2050, so we scale historical load profiles to the 2050 U.S. Energy Information Administration (EIA) projected total demand of 479 TWh (EIA 2017a), representing 36\% growth over the 2016 demand of 351.5 TWh (Potomac Economics 2017).

For renewable energy penetration, we begin with the amount of wind and solar existing or under development at the end of 2016: 19,500 MW of wind (resulting in a 15\% annual wind

\footnotetext{
${ }^{3}$ This is analogous to using storage to avoid renewable energy curtailment because both increase the utilization of capital-intensive power plants and lower their cost of energy.
} 
penetration and about 1,000 MW of PV (Potomac Economics 2017). ${ }^{4}$ We then add different mixes of wind and solar until we achieve the Wind Vision scenario of $55 \% \mathrm{VG}$, meaning exactly $55 \%$ of the total annual electricity demand is met by wind and solar: ${ }^{5}$

- Wind Vision: 44\% wind, $11 \% \mathrm{PV}$

- Minimum curtailment: $37 \%$ wind, $18 \%$ PV (described in Section 4.1)

- Equal mix: $27.5 \%$ wind, $27.5 \%$ PV.

Wind-generation profiles are from the NREL Wind Toolkit (Draxl et al. 2015). Hourly outputs are generated for 7,800 individual sites, with each site ranging in size from 2 to $16 \mathrm{MW}$ depending on resource availability within the gridded resource database. This provides a total of $117 \mathrm{GW}$ of potential capacity. We first establish a "base" amount of wind by matching locations of existing wind capacity in ERCOT (FAA 2017) to our set of simulated wind outputs. Because our wind generation profiles assume 100-m hub heights, we downscale the profiles to match historical generation levels, which are from wind turbines with lower hub heights. We then aggregate the remaining wind into four hundred 250-MW clusters based on the proximity of wind sites.

When adding wind generation to our scenarios, we first evaluate each cluster for its incremental value, or the sum of its energy and capacity values. We calculate energy value by multiplying the energy production in each hour by the marginal energy value in that hour using the 2016 price/net-load relationship (shown in the appendix). The net load is the normal demand minus actual wind generation in ERCOT. ${ }^{6}$ We estimate capacity value by multiplying the capacity credit (fraction of capacity available during periods of high net demand) by the assumed annualized value of new capacity in ERCOT (\$97/kW-year) (Newell et al. 2014). The capacity credit is estimated using the capacity factor approximation approach, taking the average capacity factor of the cluster during the top 100 load hours (Keane et al. 2011). After the cluster with the highest value is determined, that cluster's profile is subtracted from the net load, and the incremental value of all remaining clusters is determined. We assume that sufficient transmission is added to avoid congestion, so all curtailment results from system generation constraints as opposed to transmission constraints. We use this iterative process to calculate the incremental value for all 400 clusters.

We take a slightly different approach to add PV, using the PV sites generated for the SunShot 2030 study (Cole et al. 2017). These sites were selected by the Regional Energy Deployment System (ReEDS) model to identify a "cost optimal" mix of locations that are relatively close to load centers but have suitable land available for large-scale development. About 215 locations

\footnotetext{
${ }^{4}$ Specifically, at the end of 2016, the PV capacity was 783.4 MW plus 208 MW planned, and the wind capacity was $18,911 \mathrm{MW}$ plus $588 \mathrm{MW}$ planned (ERCOT 2017b). For comparison, national penetration of wind in 2016 was about 5.5\%, with state-level penetrations as high as $37 \%$ in Iowa (EIA 2017b). However, other states are interconnected, so achieving these penetrations can be technically easier than it is in ERCOT, which has a largely isolated grid.

${ }^{5} \mathrm{VG}$ penetration in our analysis is defined as the actual annual VG generation (after curtailment) divided by total generation from all resources.

${ }^{6}$ Net load was calculated by subtracting historical aggregated wind from aggregated load. We only include wind in our net load calculation because of the very small penetration of solar in ERCOT in 2016. Wind data were obtained from ERCOT (2017c).
} 
representing about $108 \mathrm{GW}$ of capacity were generated. We simulate PV at each site using the System Advisor Model to generate hourly profiles for the 6 years of study data (NREL 2016).

We use the 2016 price/net-load relationship to calibrate the aggregated minimum generation levels for the fossil and nuclear (thermal) generation fleet in ERCOT. In 2016, the minimum output from the thermal fleet in ERCOT was about 14,000 MW from about 2 to 4 a.m. on March 23 during a period with relatively low load and high wind output (Figure 1). During this period, the day-ahead price for energy fell to below $\$ 9 / \mathrm{MWh}$ in all zones (with an average of about $\$ 5 / \mathrm{MWh}$ across all zones), indicating that the thermal fleet was approaching its minimum generation levels, and additional increases in wind would have required de-committing additional units (ERCOT 2017d). We assume only a modest increase in grid flexibility between now and 2050 based on the most conservative coal-retirement scenario in the EIA Annual Energy Outlook (EIA 2017a) (about $3 \mathrm{GW}$ of capacity retired). We also assume that all $5 \mathrm{GW}$ of existing nuclear capacity receive a license extension (or are replaced with new capacity) and operate to at least 2050. These assumptions allow for a minimum generation level of about $12,000 \mathrm{MW}$ from thermal plants after accounting for nuclear refueling and thermal plant maintenance outages, which often occur during the spring. ${ }^{7}$

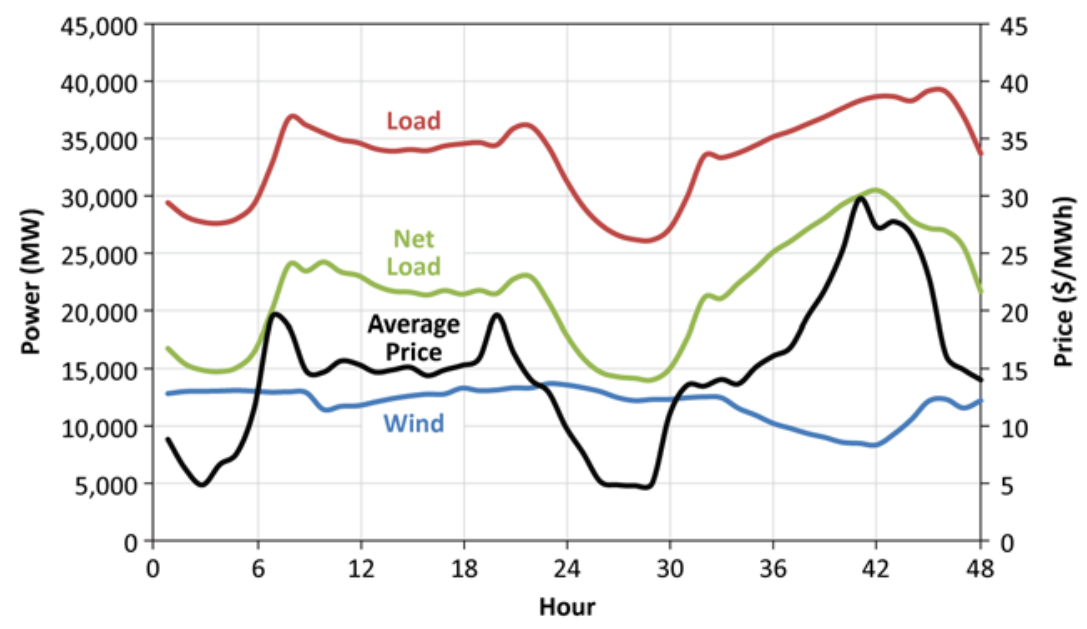

Figure 1. Actual load, wind, and average price conditions in ERCOT on March 22-23, 2016

\section{Results}

This section shows the results of our analyses, including the amount of curtailment in no-storage scenarios (Section4.1), the impact of storage size on curtailment (Section 4.2), and implications for storage value and deployment (Section 4.3).

\subsection{Curtailment in No-Storage Scenarios}

Here we describe our scenarios as well as the curtailment patterns in the scenarios without energy storage.

\footnotetext{
${ }^{7}$ All of ERCOT's nuclear power plants were operating at $100 \%$ capacity on March 23 . https://www.nrc.gov/reading-rm/doc-collections/event-status/reactor-status/2016/20160323ps.html
} 


\subsubsection{Base Curtailment Levels}

Although we focus on these 55\% VG scenarios, Figure 2 shows curtailment over a range of VG penetrations with no energy storage. Figure 2a shows the VG curtailment rate (percentage of VG potential curtailed) as a function of penetration for our three scenarios as well as the extreme cases of only wind and only solar. Figure $2 \mathrm{~b}$ shows the absolute amount of VG curtailment. These and all subsequent figures show the results using data from all six years. Year to year variability will be analyzed in future work, with sample results provided in the Appendix.

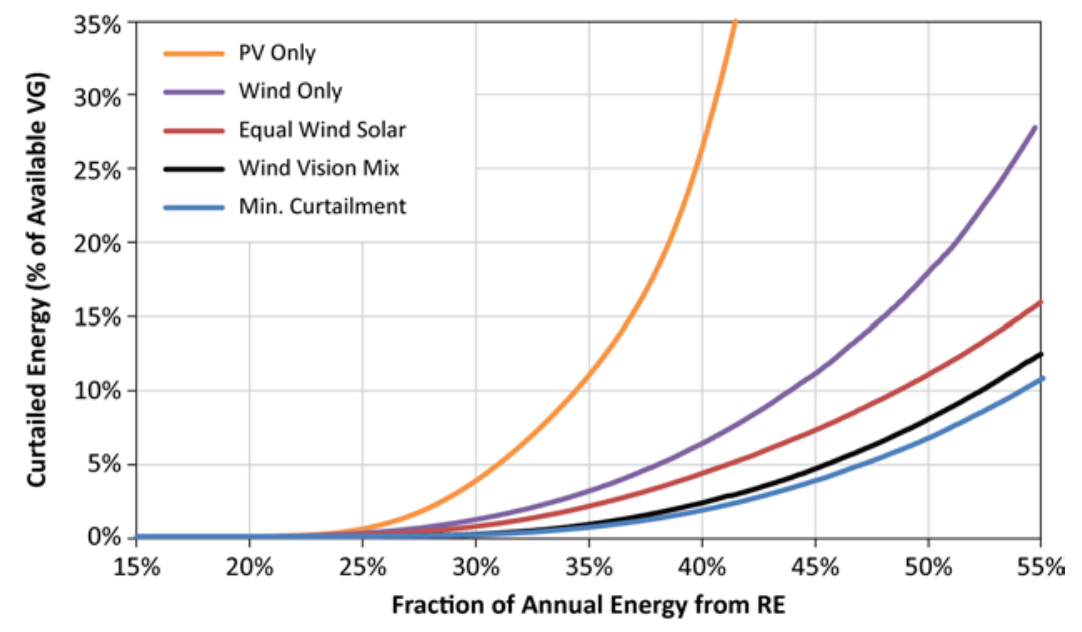

a) Total curtailment rate $(\%)$

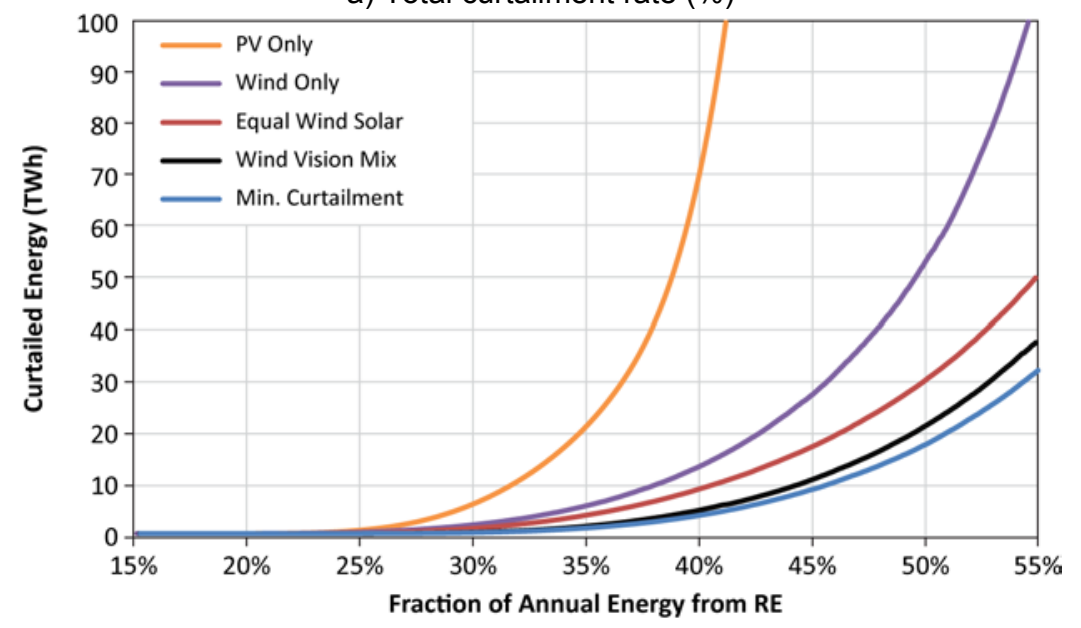

b) Total curtailment (energy)

Figure 2. Total VG curtailment rate (a) and energy curtailed (b) under increasing VG penetrations, with different mixes of wind and solar and no energy storage

The economic consequences of increased curtailment can be expressed using one of several metrics, including declining value or increased costs. As an increasing fraction of wind or solar is curtailed, it no longer displaces fossil generation, reducing its economic or environmental value to the energy system and society as a whole (Mills and Wiser 2012). Alternatively, (from the perspective of costs), curtailment acts to increase the levelized cost of energy, as the generators' fixed costs must be spread across fewer units of energy (Denholm and Margolis 2016). 
Figure 2 also demonstrates the complementary nature of wind and solar. Using the Wind Vision mix of resources (a $4: 1 \mathrm{wind} /$ solar ratio), $55 \% \mathrm{VG}$ penetration can be achieved with nontransmission-related curtailment of only about $12 \%$, even without adding storage or sharing energy with neighboring regions. The wind-only case results in about three times the amount of curtailed energy compared with the Wind Vision mix (about $107 \mathrm{TWh}$ vs. $38 \mathrm{TWh}$ ) at 55\% VG. The PV-only case cannot achieve much greater than $40 \%$ penetration without storage owing to the mismatch of supply and demand. By modifying the wind/solar mix, curtailment can be reduced below the level resulting from the Wind Vision mix, as shown in the minimumcurtailment curve. Figure 3 shows the amount of curtailed VG at 55\% penetration for different mixes of wind and solar based on the REFlex simulations. Along all points on the graph, the sum of wind and solar penetration (bottom and top x-axes) is 55\%. The three vertical lines represent the study scenarios, so they match the study scenario curtailments at $55 \%$ shown in Figure 2 . The mix that minimizes curtailment has a wind/solar ratio of about 2.2:1.

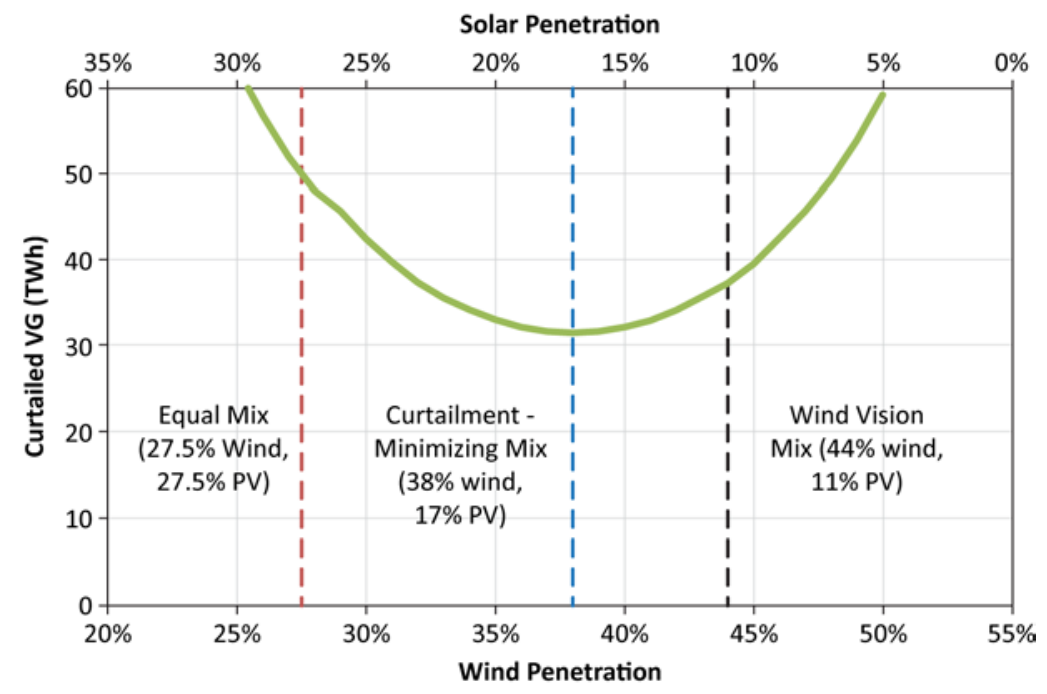

Figure 3. Total VG curtailed at an annual VG penetration of $55 \%$ as a function of wind/solar mix, with no energy storage

\subsubsection{Curtailment Patterns}

Historically, curtailment has been driven largely by transmission constraints because of limited transmission capacity for delivering wind electricity from the point of generation to load centers (Bird et al. 2016). Total curtailment of wind in 2016 in ERCOT was about 2\% (Potomac Economics 2017). Following historical development in ERCOT, we assume that adequate new transmission is constructed to avoid significant transmission-related curtailment. For a system with adequate transmission capacity, curtailment is driven by a combination of grid flexibility and patterns of renewable supply and electricity demand. The ability to reduce curtailment with storage depends on the daily and seasonal patterns of curtailment. Wind and PV have different diurnal and seasonal production patterns, which impact the duration of curtailment events and required storage durations. As an example, Figure 4 shows curtailment patterns during a 48-hour period (starting at 8 p.m. on January 20) for the three different scenarios at $55 \% \mathrm{VG}$ before the addition of storage. This example uses wind and load patterns from 2012. In the equal-mix scenario, curtailment is dominated by high-peak-power PV curtailment events. Eliminating curtailment would require storage with high power capacity but with relatively few hours of 
energy capacity. In contrast, curtailment events in the Wind Vision scenario have lower peak power but can occur over long periods. Starting at about 8 p.m. on January 20, curtailment lasts for 19 hours.

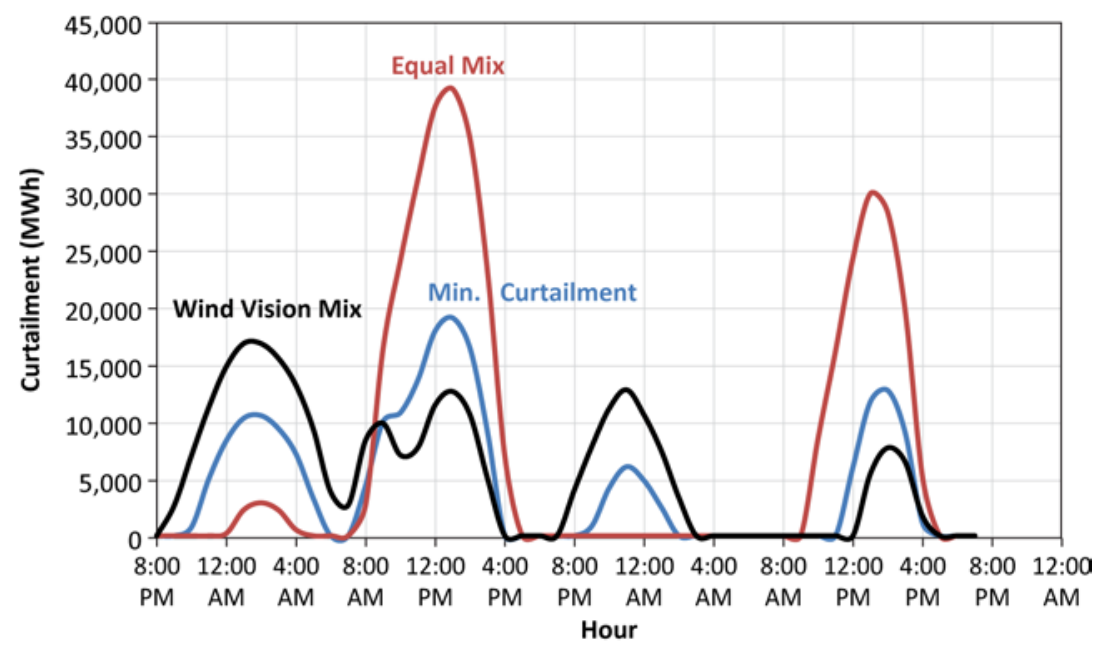

Figure 4. Simulated curtailment during January 20-21 in ERCOT with no storage using 2012 wind, solar, and load patterns

The scenarios have a large range in both instantaneous curtailment (power) and length of curtailment events, as illustrated in Figure 5 and Figure 6. Figure 5 shows a duration curve of the curtailment events. Curtailment occurs during 30\% to $33 \%$ of the simulated hourly periods. Levels of instantaneous curtailment are very high, particularly for the equal-mix scenario, which has relatively high PV.

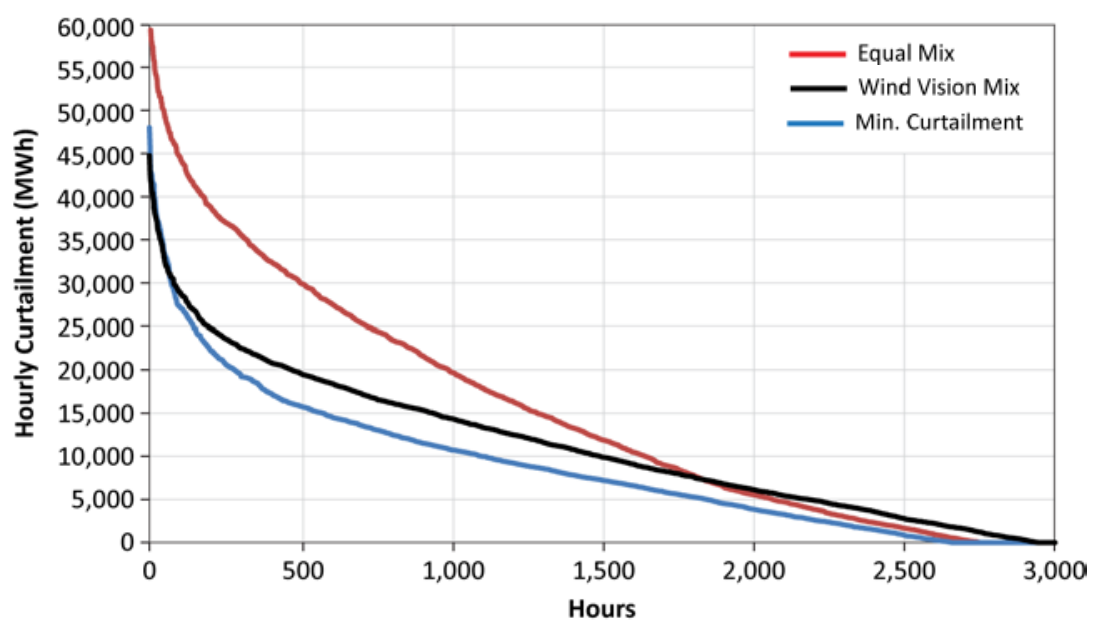

Figure 5. Duration curve of curtailment at 55\% VG in ERCOT with no storage using 2012 wind, solar, and load patterns

Figure 6 shows the distributions of curtailment-event duration (Figure 6a) and energy (Figure 6b) at 55\% VG in each scenario with no storage using 2012 wind, solar, and load patterns. Long curtailment events are most common in the Wind Vision scenario, with $32 \%$ of events occurring over at least 10 hours. The longest curtailment event in the Wind Vision scenario lasts about 90 hours. In contrast, the equal-mix scenario has shorter curtailment events with higher average power and often with greater total energy than in the Wind Vision scenario. 


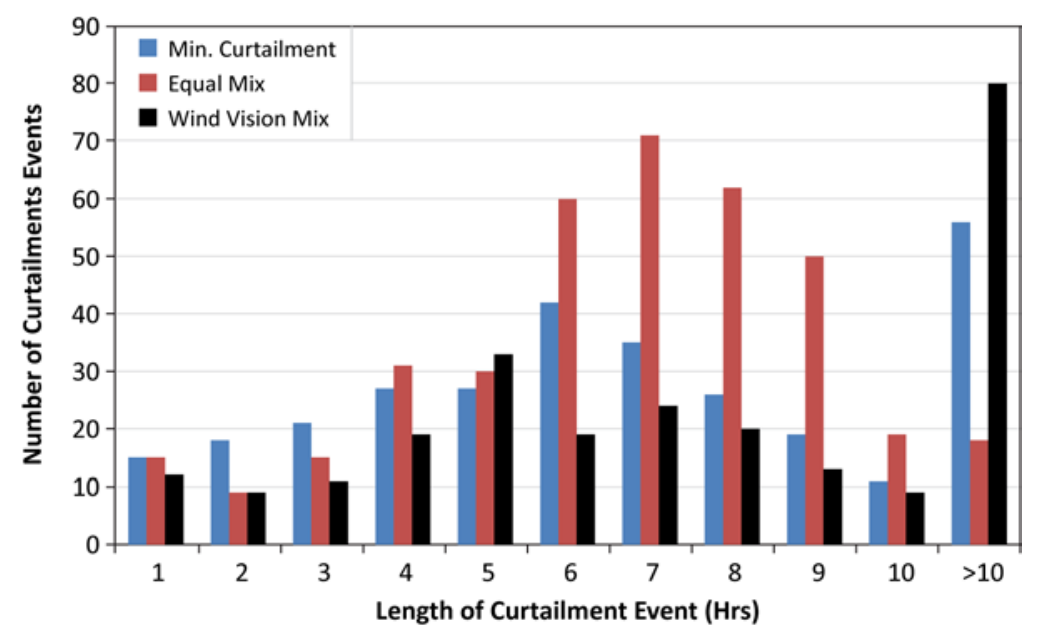

a) Distribution of duration

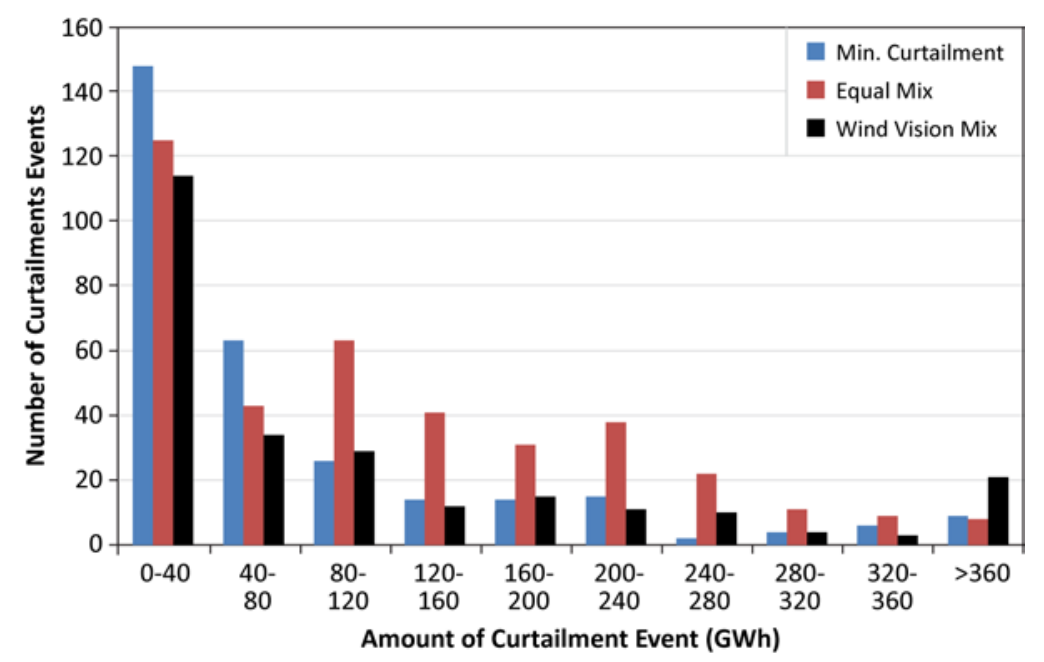

b) Distribution of energy

Figure 6. Distributions of duration (a) and energy (b) of curtailment events with no storage using 2012 wind, solar, and load patterns

These summary statistics provide only a partial quantification, particularly owing to the shape of the VG curtailment events and the variability of curtailed energy during each event. The following section examines storage plant operation to quantify the ability of storage to mitigate curtailment. 


\subsection{Impact of Storage Capacity on Curtailment}

The ability to avoid curtailment is a function of both the power and energy capacities of the energy storage device. We perform simulations with varying energy storage sizes to examine curtailment reduction with a focus on the role of duration. The results show the first 4-8 hours of storage reducing curtailment significantly, with the avoided-curtailment benefit diminishing as more storage duration is added - suggesting a limited need for multi-day or seasonal storage at VG penetrations of $55 \%$ or less.

Figure 7 (next page) illustrates the substantial curtailment reduction possible with relatively short-duration storage. It shows the total VG curtailment (Figure 7a) and fraction of potential VG curtailed (Figure $7 \mathrm{~b}$ ) at $55 \% \mathrm{VG}$ for increasing quantities of storage power capacity with 4,8 , or 12 hours of storage duration. ${ }^{8}$ Without any storage, about $11 \%-16 \%$ of VG energy is curtailed. The vertical line in each chart denotes the addition of storage with a power capacity of $8.5 \mathrm{GW}$, or the amount built in the Wind Vision study. Installing this capacity would represent replacing about one-third of the projected peaking capacity (mostly combustion turbines) in ERCOT with storage by $2050 .{ }^{9}$ At this level of power capacity, adding the first 4 hours of storage reduces the curtailment rate by $3-5$ percentage points to $11 \%$ or less across all scenarios. With 8 hours of storage, curtailment is $9 \%$ or less across all scenarios.

\footnotetext{
${ }^{8}$ These durations approximate three general classes of storage that have been installed or proposed. A number of 4hour lithium-ion batteries have been installed for peaking capacity (U.S. DOE 2017). Longer-duration (about 8 hours) batteries have seen less deployment but could represent flow batteries (Akhil et al. 2015). Even longerduration (12 hours or more) storage represents pumped hydro or CAES.

${ }^{9}$ The EIA AEO 2017 projects about $28 \mathrm{GW}$ of peaking capacity in ERCOT in 2050, up from about $20 \mathrm{GW}$ in 2016 (EIA 2017a). Note that the Wind Vision study assumes storage capacity in Texas would be provided by longduration CAES with at least 12 hours of capacity. At the time of that study, cost projections did not result in costcompetitive battery storage.
} 


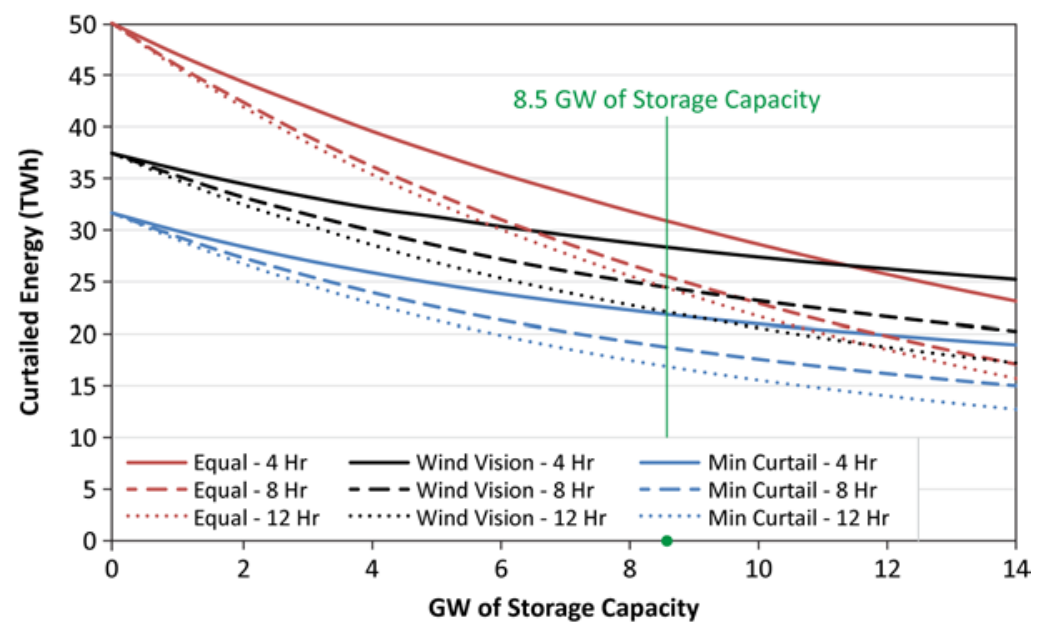

a) Total curtailment

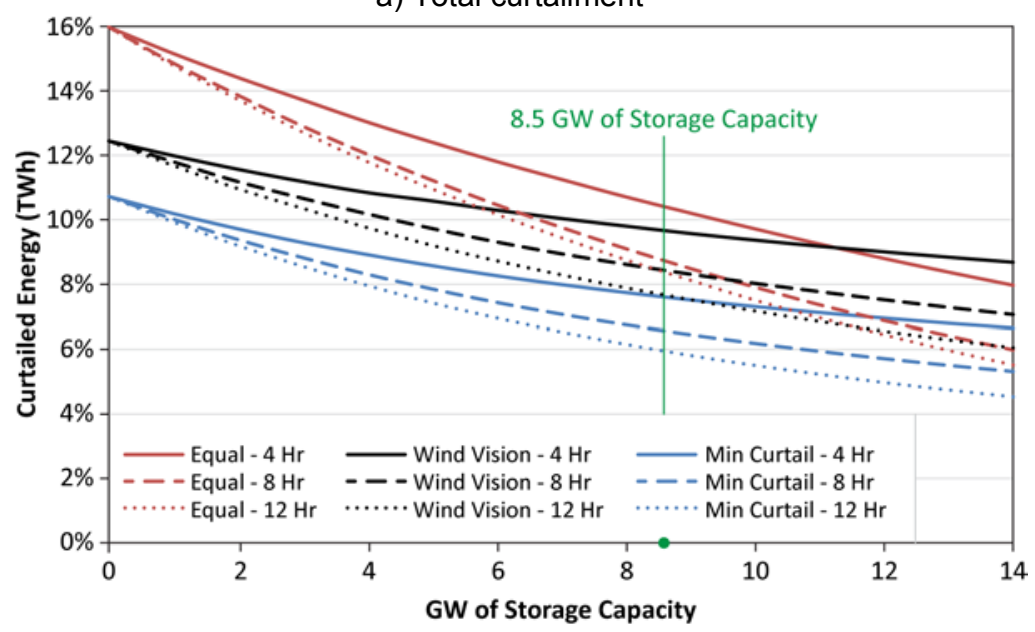

b) Curtailment rate

Figure 7. Total curtailment (a) and curtailment rate (b) at $55 \%$ VG as a function of storage power capacity for the three study scenarios at varying storage durations

Figure 7 also shows that additional storage duration and power capacity provide diminishing avoided-curtailment returns. To clarify this trend, Figure 8 shows the amount of curtailed energy avoided in the equal-mix and Wind Vision scenarios at 55\% VG as a function of power capacity and duration. Avoided curtailment is calculated by comparing the amount of curtailment in the system without storage at $55 \% \mathrm{VG}$ to the amount of curtailment with storage at $55 \% \mathrm{VG}$, so it includes both curtailment that is stored and curtailment avoided because less VG was needed to achieve the $55 \%$ penetration level. ${ }^{10}$ The solid lines show the curtailment avoided for a 4-hour storage device. The equal-mix device avoids the most curtailment in part because there is more curtailed energy to start with but also because the greater amount of PV leads to shorter-duration curtailment events. As a result, $2 \mathrm{GW}$ of 4-hour storage avoids about $6 \mathrm{TWh}$ of curtailed VG in

\footnotetext{
${ }^{10}$ For example, curtailment at 55\% VG in the Wind Vision scenario is about $34.0 \mathrm{TWh}$. If we add $8.5 \mathrm{GW}$ of 8 -hour storage to this scenario without reducing the wind or solar buildout, curtailment drops to $24.3 \mathrm{TWh}$, and the actual VG penetration increases to $57 \%$ (after storage losses). Therefore, $55 \% \mathrm{VG}$ can be achieved by building less wind and solar. When we recalculate the amount of VG needed to achieve 55\%, the curtailment drops to $19.2 \mathrm{TWh}$, or a reduction of 14.8 TWh. However, less than half (about 7.2 TWh) of this avoided curtailment is from stored energy (after losses), and the rest is from VG that did not need to be added.
} 
the equal-mix scenario, while the same amount of storage avoids about 3 TWh in the Wind Vision scenario. In the equal-mix scenario, adding another 4 hours of storage duration to the 2GW device only avoids about 2 TWh (about one-third of the amount avoided by the first 4 hours of duration) because the first 4 hours absorbed most of the PV curtailment that could be absorbed by a 2-GW device. The third 4-hour block of storage avoids very little additional curtailment in the equal-mix scenario. Avoided curtailment also decreases for each additional unit of storage duration in the Wind Vision scenario, but the proportional decrease is less than in the equal-mix scenario.

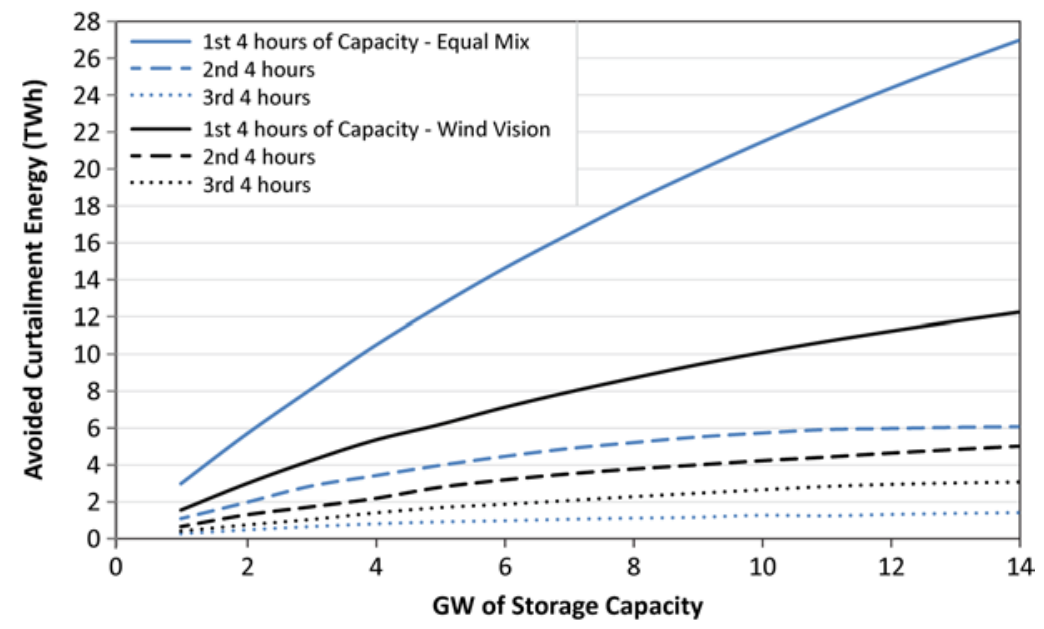

Figure 8. Avoided curtailment at $55 \%$ VG as a function of storage power capacity for the equal-mix and Wind Vision scenarios with varying amounts of additional storage duration

Figure 9 further clarifies the diminishing returns achieved with greater storage duration. Figure 9a shows the total curtailment for the three study scenarios, but unlike the previous figures, we hold the power constant and vary the duration of storage capacity. In this case, we use the storage capacity developed in the Wind Vision study $(8.5 \mathrm{GW})$. It shows the rapid decline in curtailment for the first 4-8 hours, then substantially diminishing reductions in curtailment beyond 8 hours. Figure $9 \mathrm{~b}$ uses the same data to show the actual avoided curtailment, measured as a percentage of the curtailment that could be avoided using a storage device with unlimited duration. The absolute amount of avoided curtailment can be calculated by multiplying the fraction avoided by the total amount avoided with an unlimited storage device, shown in the text boxes within the figures. 


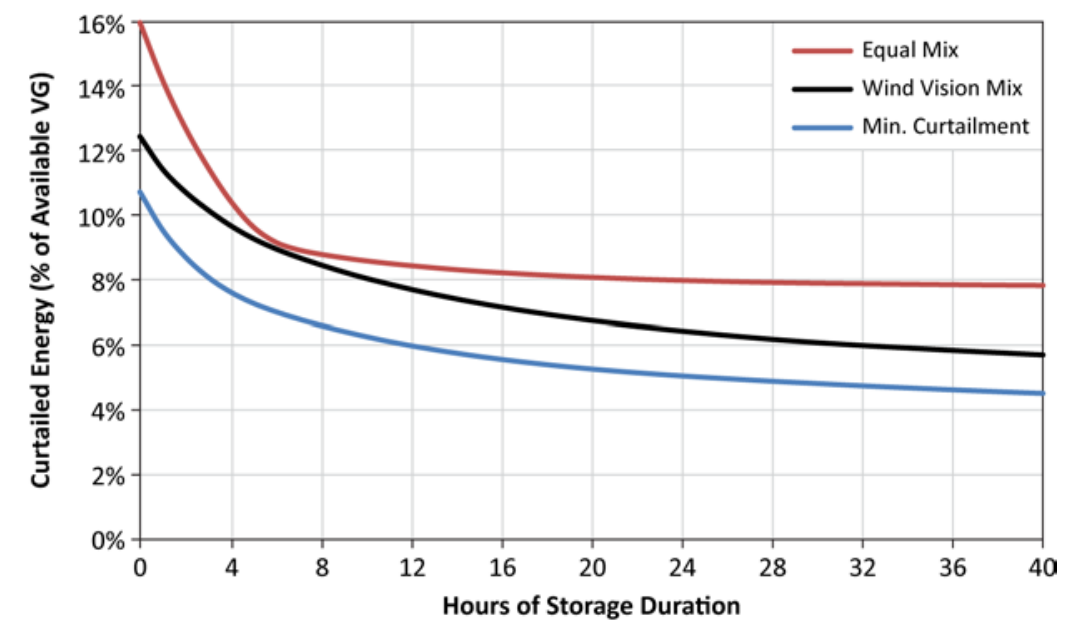

a) Total curtailment

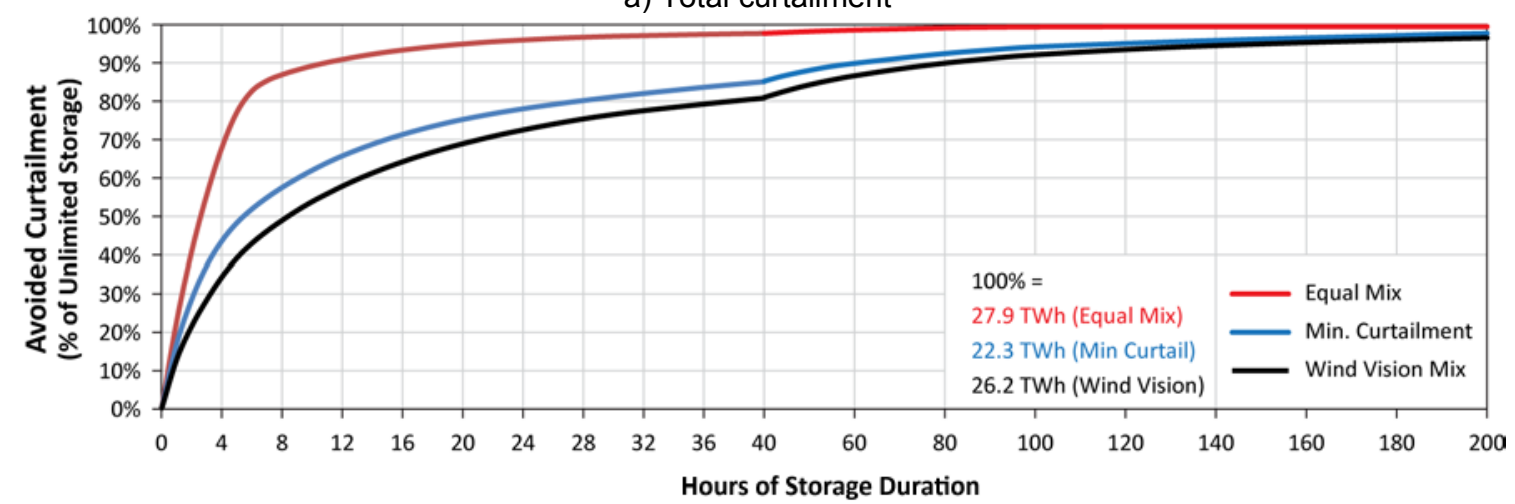

b) Avoided curtailment (shown as a percentage of curtailment avoided using an unlimited-duration storage device) note the different $\mathrm{x}$-axis intervals after 40 hours

Figure 9. Total curtailment (a) and avoided curtailment (b) at $55 \%$ VG as a function of storage duration assuming $8.5 \mathrm{GW}$ of storage power capacity for the three study scenarios

In the equal-mix scenario, a 4-hour device avoids about $70 \%$ of the energy that would have been avoided by a device with unlimited duration, rising to over $85 \%$ at 8 hours. Alternatively, in the Wind Vision scenario, avoided curtailment is about 35\% at 4 hours, $50 \%$ at 8 hours, and still less than $60 \%$ at 12 hours. To completely eliminate curtailment would require a device with about 50 hours of duration in the equal-mix scenario and about 250 hours in the Wind Vision scenario. This demonstrates the challenge of avoiding curtailment in the high wind scenarios due to long duration events (as well as often limited time between events to fully utilize stored VG). As shown previously, this implies that it is easier to reduce curtailment with storage in high solar cases, although with the important caveat that high solar cases start with higher levels of curtailment.

Overall, these results show that VG curtailment at a 55\% penetration can be reduced significantly with storage devices with 8 hours or less of duration. While these results provide a general indication of the ranges of storage that might be required to reduce curtailment, they do not provide deep insight into the tradeoff between adding power and energy when considering the relative economics of storage devices. The following section provides additional analysis of the likely tradeoff between power and energy capacity faced by storage developers under increased VG penetration. 


\subsection{Impact of Storage Duration on Value}

The results in Section 4.2 indicate the avoided-curtailment benefits of adding storage with relatively short durations, but they do not consider energy storage's overall value. Here we analyze the impact of storage duration on value and highlight the potential economic advantage of storage durations of about 4 hours, which potentially capture the most value from providing peak capacity.

We consider a limited set of values (capacity and energy) because the goal of our value analysis is to examine the relative change in value as a function of storage duration, as opposed to the absolute value of energy storage. A market assessment would consider the broader array of services, including transmission and distribution (T\&D) deferral and a variety of operating reserves, with the caveat that the relatively small market for many reserve products could result in saturation by shorter-duration storage, demand response, and provision from curtailed renewables (Ma et al. 2014).

Capacity value - the ability of storage to replace conventional peaking capacity - is the product of a storage device's capacity credit and the cost of the conventional capacity displaced. The concept of capacity credit is applicable to all generator types and reflects a generator's availability during periods of peak demand (Keane et al. 2011). The ability of storage to provide significant capacity credit depends on having a sufficient quantity of stored energy during periods of peak demand, and it is generally a function of the shape of the net demand curve. There has been limited analysis of the capacity credit of storage as a function of storage duration. Figure 10 summarizes two estimates, with the left y-axis representing the capacity credit measured as a function of nameplate (power) capacity. The curve from Sioshansi, Madaeni, and Denholm (2014) represents the average of estimates from an analysis of five different U.S. regions using historical load data, and it does not consider the impact of VG on net-load shapes. This result suggests that, for a system without significant penetration of VG, the capacity credit of a 4-hour device is about 75\%. However, several U.S. independent system operators (ISOs) assume 4-hour storage devices can provide full capacity value (CAISO 2017; Johal, Tome, and Collison 2016). For the capacity credit curve under this assumption, we divide the number of hours of energy by 4 for devices with less than 4 hours of capacity (e.g., a 2-hour storage device would need to discharge at $50 \%$ of nameplate power capacity for 4 hours, resulting in a $50 \%$ capacity credit). The results of this approach are labeled as the "ISO 4-hour rule" in Figure 10.

Previous analyses have also demonstrated that PV can change the net load shape and increase the capacity credit of storage (Perez et al. 2008; Jorgenson, Denholm, and Mehos 2014). We do not consider the impact of PV penetration on capacity credit in this analysis.

The right y-axis in Figure 10 translates the capacity credit into an annualized capacity value by multiplying the capacity credit by the annualized cost of new capacity. This assumes that storage will replace a conventional peaking gas turbine and offset its costs with an annualized avoided capacity cost of $\$ 97 / \mathrm{kW}$-year (Newell et al. 2014). This value assumes that the system actually needs new capacity and that there are appropriate mechanisms for storage to be compensated for providing this service. 


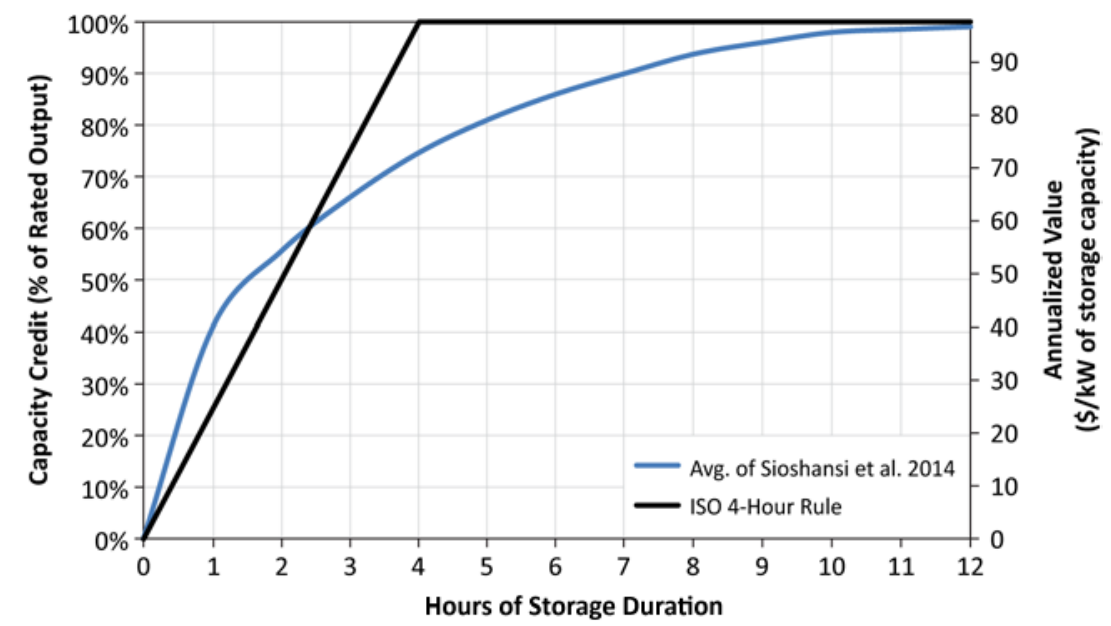

Figure 10. Capacity credit and annualized capacity value of storage as a function of hours of storage (value assumes avoided $\$ 97 / \mathrm{kW}$ of firm capacity)

The second value source that we estimate is energy value from energy price arbitrage/time shifting. This value stems from storing otherwise-curtailed energy and from arbitraging price differences of energy from thermal plants (i.e., from storing more efficient off-peak thermal generation and displacing less efficient peaking resources). This value is highly sensitive to assumed VG penetration and mix, fuel prices, carbon costs, and the amount of storage on the system. To provide a range of cases, we evaluate three combinations of VG penetration, VG mix, natural gas price, and carbon dioxide $\left(\mathrm{CO}_{2}\right)$ cost (Table 1). Figure 11 provides the annual energy value for the three cases.

Table 1. Cases Evaluated

\begin{tabular}{lllll}
\hline Name & $\begin{array}{l}\text { VG } \\
\text { Penetration }\end{array}$ & Wind/Solar Ratio & $\begin{array}{l}\text { Natural Gas Price } \\
\text { (\$/MMBTU) }\end{array}$ & $\begin{array}{l}\mathbf{C O}_{2} \text { Cost } \\
\text { (\$/ton) }\end{array}$ \\
\hline Low Value & $35 \%$ & $2.2: 1$ & 4 & 0 \\
Medium & $45 \%$ & $4: 1$ & 5 & 20 \\
High Value & $55 \%$ & $1: 1$ & 6 & 40 \\
\hline
\end{tabular}




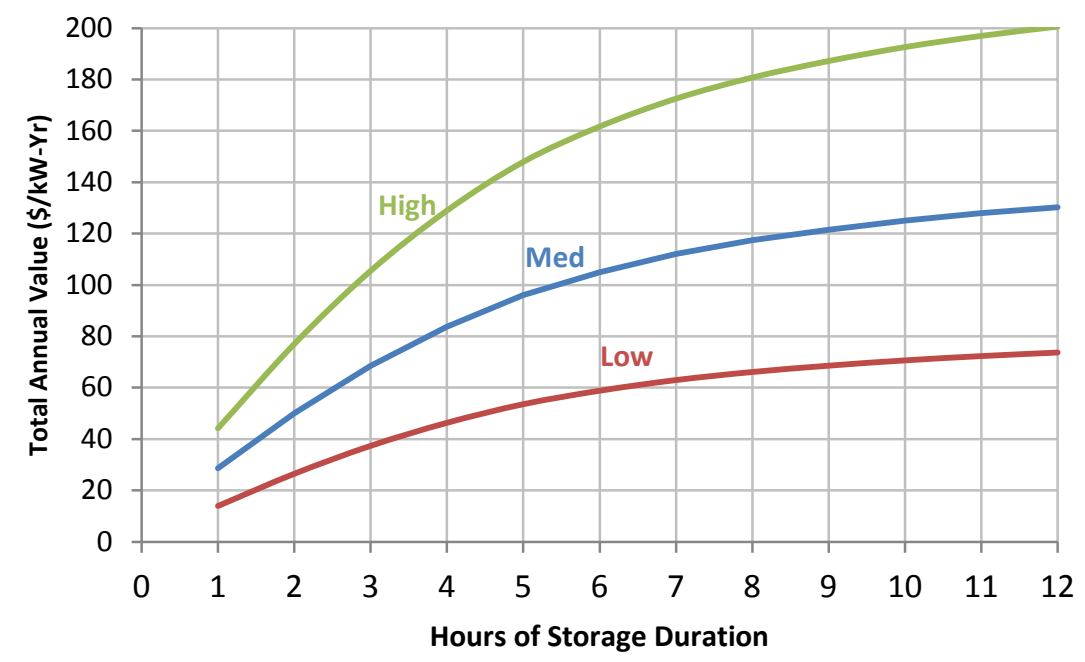

Figure 11. Energy value of energy storage under different cases

Figure 12 illustrates total value as a function of storage duration, suggesting declining incremental value as additional duration is added. ${ }^{11}$ Combining the two possibilities for capacity value (Figure 10) and the three cases for energy value (Figure 11) yields six possibilities for total value. The left y-axis shows annual value, and the right y-axis shows the net present value assuming a 15-year system life and a 5\% discount rate. This result can also be expressed as a rough approximation of the overnight capital cost of a storage device (expressed as cost per kilowatt of installed capacity); although it does not include the impact of operations and maintenance $(\mathrm{O} \& \mathrm{M})$ costs or any salvage value of the project at the end of the 15 -year life. Again, this result only considers a subset of possible values.

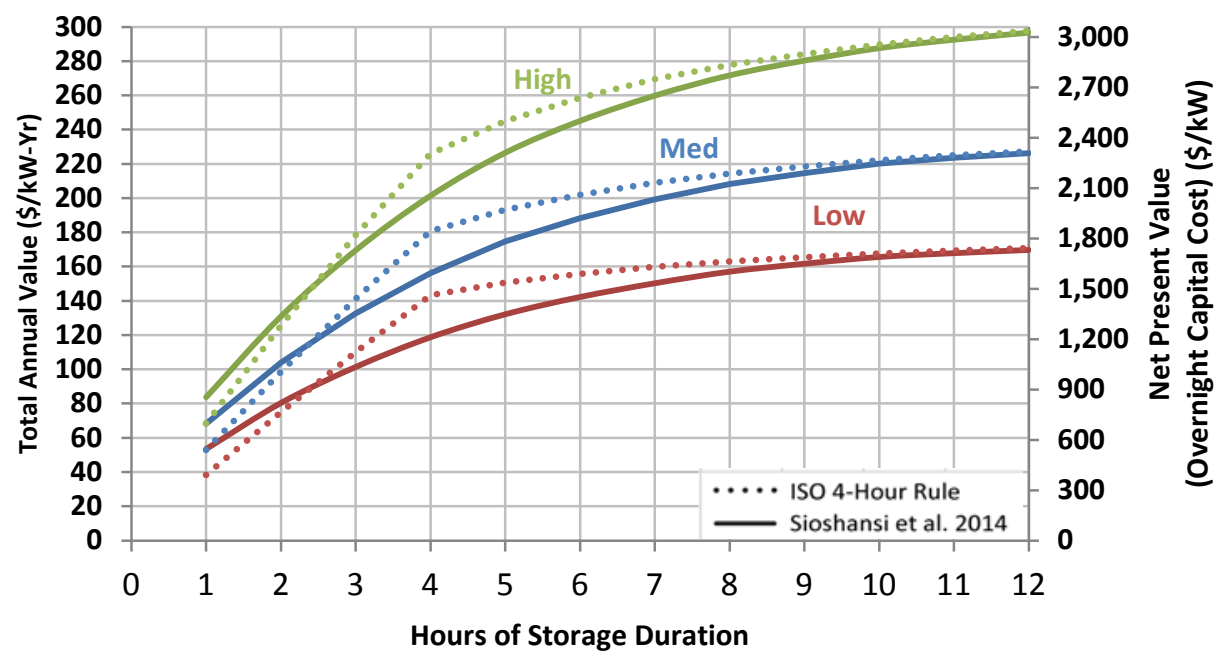

Figure 12. Total value of storage as a function of storage duration

A developer must compare the incremental costs to the incremental value of the next additional unit of energy storage. The cost of the energy component of a storage device does not necessarily

\footnotetext{
${ }^{11}$ This analysis assumes development of storage by an entity that can monetize multiple value streams including capacity at the avoided cost a new gas turbine.
} 
scale in a linear manner, but the results in Figure 12 can provide some insight into the costcompetitiveness of adding additional hours of storage capacity. Figure 13 uses the "medium energy" data (blue lines) from Figure 12 to estimate the value of adding incremental hours of storage. The left y-axis represents the annual value of an additional kilowatt-hour of energy capacity. The first hour of storage has the highest value, particularly when using the capacity value method from Sioshansi, Madaeni, and Denholm (2014), because this first hour receives a relatively high capacity credit. Because the ISO 4-hour method assumes $100 \%$ capacity credit for a 4-hour device, the incremental value drops for a longer duration device to only the value of energy price arbitrage/time shifting. The right y-axis translates the results into a net present value, using the same assumptions as previously described. As a result, this value represents a rough approximation of the breakeven cost for an incremental hour of energy storage. ${ }^{12}$ Repeating the analysis for different VG penetrations and storage capacities produces different absolute values, but all simulations reveal a similar shape with a significant decline in value beyond 4 hours of capacity.

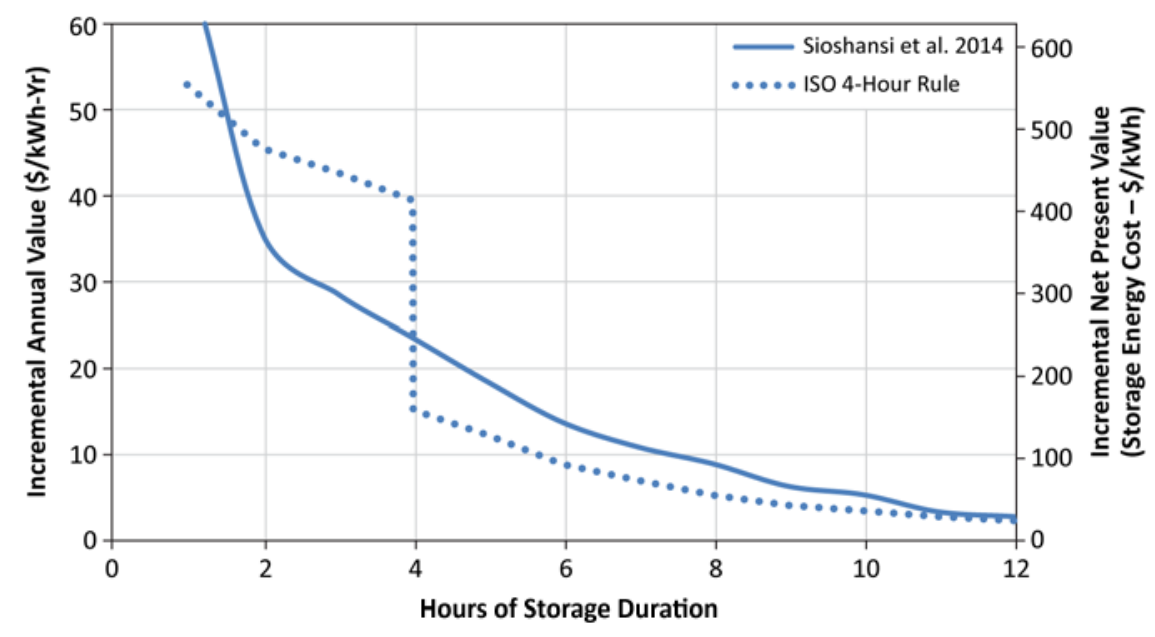

Figure 13. Incremental value of energy storage, medium-value case

Overall, these results demonstrate that once a storage device achieves the bulk of its value from the first few hours (from providing capacity and a large fraction of the energy arbitrage/avoided curtailment value), the incremental value of additional energy is relatively low under a range of scenarios. While the results in Figure 12 and Figure 13 do not capture the full value of energy storage providing multiple services, they do indicate that near-term applications for energy storage that focus on providing capacity and load-shifting services may place a premium on short-duration devices until there is a more significant cost reduction in the energy component of large-scale energy storage.

\footnotetext{
${ }^{12}$ For a battery, this represents the cost of only the battery module, assuming no additional power-related components are needed.
} 


\section{Conclusions}

With improving wind turbine performance and declining costs of PV, growth of these VG resources likely will continue, within constraints imposed by increasing levels of curtailment. There are multiple pathways to improved system flexibility and increased VG integration including greater interconnections to surrounding regions, demand response, and increased generator flexibility - this report's focus on energy storage does not imply that storage is required to integrate $\mathrm{VG}$ at penetrations up to the $55 \%$ contemplated in this analysis. In fact, energy storage has historically been considered among the more expensive options owing to high capital costs and energy losses. However, declining storage costs have raised the possibility that storage could see significant deployment strictly on an economic basis as an alternative to conventional peaking capacity. This analysis suggests that economic deployment of storage used for the provision of peak capacity could provide a substantial resource to reduce VG curtailment and increase VG penetration.

Our modeling shows that the amount of VG curtailed is a function of wind and PV generation patterns and the size of energy storage deployed. Overall, our results suggest that relatively short-duration energy storage might offer an effective path to integrating VG at penetrations up to $55 \%$. Across all the mixes of wind and solar resources analyzed, at least half of the potential avoided-curtailment benefits are realized with 8 hours of storage, and the first 4 hours provide the largest benefit. A 4-hour duration also offers a relatively high capacity value, which is critical to the economics of storage. Cost improvements might make storage with durations of 6 or even 8 hours viable, but there appears to be little value in deploying very-long-duration or seasonal storage at $\mathrm{VG}$ penetrations up to $55 \%$.

Further analysis is required to analyze VG penetrations beyond $55 \%$ and the seasonal impact of VG generation. Long-duration storage with extremely low energy costs (such as fuels production) may be able to mitigate long-duration curtailment events that will increasingly occur in the spring. This requires understanding the tradeoffs with lower roundtrip efficiencies that are typical in these technologies, as well as other grid flexibility options to increase VG penetration in decarbonized energy scenarios. Finally, the impact of extremely large storage deployments must be considered. A system with adequate capacity (from any combination of renewables and conventional generation) will reduce the capacity value of storage, which provides a large fraction of storage's value, and further storage deployments would have greater dependence on energy-shifting value. As storage costs continue to decline and technologies are developed, the interplay between power and energy will require continued analysis to determine the costoptimal mix of flexibility technologies for integration of $\mathrm{VG}$ resources. 


\section{References}

Akhil, A. A., G. Huff, A. B. Currier, B. C. Kaun, D. M. Rastler, S. B. Chen, A. L. Cotter, D. T. Bradshaw, and W. D. Gauntlett. 2015. DOE/EPRI Electricity Storage Handbook in Collaboration with NRECA. SAND2015-1002. Albuquerque NM: Sandia National Laboratories. http://www.sandia.gov/ess/publications/SAND2015-1002.pdf.

Bird, L., D. Lew, M. Milligan, E. Maria Carlini, A. Estanqueiro, D. Flynn, E. Gomez-Lazaro, H. Holttinen, Nickie Menemenlis, A. Orths, Peter Børre Eriksen, J. C. Smith, L. Soder, P. Sorensen, A. Altiparmakis, Y. Yasuda, and J. Miller.2016. "Wind and Solar Energy Curtailment: A Review of International Experience." Renewable and Sustainable Energy Reviews 65: 577-86. ISSN 1364-0321. http://dx.doi.org/10.1016/j.rser.2016.06.082. http://www.sciencedirect.com/science/article/pii/S1364032116303161

Blanco, H., and A. Faaij. "A review at the role of storage in energy systems with a focus on Power to Gas and long-term storage." Renewable and Sustainable Energy Reviews 81 (2018): 1049-1086.

Bloom, Aaron, Aaron Townsend, David Palchak, Joshua Novacheck, Jack King, Clayton Barrows, Eduardo Ibanez, Matthew O'Connell, Gary Jordan, Billy Roberts, Caroline Draxl, and Kenny Gruchalla. 2016. Eastern Renewable Generation Integration Study. NREL/TP-6A2064472. Golden, CO: National Renewable Energy Laboratory.

Brinkman, G. 2015. Renewable Electricity Futures: Operational Analysis of the Western Interconnection at Very High Renewable Penetrations. NREL/TP-6A20-64467. Golden, CO: National Renewable Energy Laboratory.

Brinkman, Gregory, Jennie Jorgenson, Ali Ehlen, and James H. Caldwell. 2016. California 2030 Low Carbon Grid Study: Analysis of a 50\% Emission Reduction in California. NREL/TP-6A2064884. Golden, CO: National Renewable Energy Laboratory.

http://www.nrel.gov/docs/fy16osti/64884.pdf.

CAISO. 2017. 2016 Annual Report on Market Issues and Performance. Folsom, CA: CAISO.

Cardwell, D., and C. Krauss. 2017. “A Big Test for Big Batteries.” The New York Times, January 14, 2017.

Cochran, J., P. Denholm, B. Speer, and M. Miller. 2015. Grid Integration and the Carrying Capacity of the U.S. Grid to Incorporate Variable Renewable Energy. NREL/TP-6A20-62607. Golden, CO: National Renewable Energy Laboratory.

http://www.nrel.gov/docs/fy15osti/62607.pdf.

Cole, Wesley, Bethany Frew, Pieter Gagnon, James Richards, Yinong Sun, Jarett Zuboy, Michael Woodhouse, and Robert Margolis. 2017 SunShot 2030 for Photovoltaics (PV): Envisioning a Low-cost PV Future. NREL/TP-6A20-68105. Golden, CO: National Renewable Energy Laboratory. https://www.nrel.gov/docs/fy17osti/68105.pdf. 
Denholm, P., and M. Hand. 2011. "Grid Flexibility and Storage Required to Achieve Very High Penetration of Variable Renewable Electricity." Energy Policy 39:1817-30.

Denholm, P., and R. Margolis. 2016. Energy Storage Requirements for Achieving 50\% Solar Photovoltaic Energy Penetration in California. NREL/TP-6A20-66595. Golden, CO: National Renewable Energy Laboratory.

Denholm, P., V. Diakov, and R. Margolis. 2015. The Relative Economic Merits of Storage and Combustion Turbines for Meeting Peak Capacity Requirements under Increased Penetration of Solar Photovoltaics. NREL/TP-6A20-64841. Golden, CO: National Renewable Energy Laboratory.

Draxl, C., A. Clifton, B. M. Hodge, and J. McCaa. 2015. "Wind Integration National Dataset (WIND) Toolkit." Applied Energy 151: 355-66.

EIA. 2017a. Annual Energy Outlook 2017. Washington, D.C.: EIA. https://www.eia.gov/outlooks/aeo/.

_. 2017b. "Electricity Data Browser." Accessed September 8, 2017. https://www.eia.gov/electricity/data/browser/.

Eichman, J., P. Denholm, J. Jorgenson, and U. Helman. 2015. Operational Benefits of Meeting California's Energy Storage Targets. NREL/TP- 5400-65061. Golden, CO: National Renewable Energy Laboratory. http://www.nrel.gov/docs/fy16osti/65061.pdf.

ERCOT. 2017a. "Hourly Load Data Archives.” Accessed September 8, 2017. http://www.ercot.com/gridinfo/load/load hist.

—. 2017b. "Summer 2017 Final Seasonal Assessment.” Published May 02, 2017. http://www.ercot.com/gridinfo/resource.

_. 2017c. "Hourly Aggregated Wind Output.” Accessed September 8, 2017. http://mis.ercot.com/misapp/GetReports.do?reportTypeId=13424\&reportTitle=Hourly\%20Aggre gated $\% 20 \mathrm{Wind} \% 20$ Output\&showHTMLView=\&mimicKey.

—. 2017d. "Market Prices.” Accessed September 8, 2017. http://www.ercot.com/mktinfo/prices.

FAA. 2017. "U.S. Federal Aviation Administration (FAA) Wind Turbine Location Data." Last Updated August 15, 2017. https://www.fws.gov/southwest/es/Energy_Wind_FAA.html.

Götz, Manuel, Jonathan Lefebvre, Friedemann Mörs, Amy McDaniel Koch, Frank Graf, Siegfried Bajohr, Rainer Reimert, and Thomas Kolb. 2016. "Renewable Power-to-Gas: A Technological and Economic Review." Renewable Energy 85: 1371-90.

Johal, H., D. Feitosa Tome, and K. Collison. 2016 Unlocking the Hidden (Capacity) Value in Energy Storage. ICF. 
Jorgenson, J., P. Denholm, and M. Mehos. 2014. Estimating the Value of Utility-Scale Solar Technologies in California under a 40\% Renewable Portfolio Standard. TP-6A20-61685. Golden, CO: National Renewable Energy Laboratory.

Keane, A., M. Milligan, C. J. Dent, B. Hasche, C. D'Annunzio, K. Dragoon, and M. O'Malley. 2011. “Capacity Value of Wind Power." IEEE Transactions on Power Systems 26(2): 564-72.

Lantz, Eric, Trieu Mai, Ryan Wiser, and Venkat Krishnan. 2016. "Long-Term Implications of Sustained Wind Power Growth in the United States: Direct Electric System Impacts and Costs." Applied Energy 179 (October): 832-46. doi:10.1016/j.apenergy.2016.07.023

Lew, D., G. Brinkman, E. Ibanez, A. Florita, M. Heaney, B.-M. Hodge, M. Hummon, G. Stark, J. King, S. A. Lefton, N. Kumar, D. Agan, G. Jordan, and S. Venkataraman. 2013. The Western Wind and Solar Integration Study Phase 2. NREL/TP-5500-55588. Golden, CO: National Renewable Energy Laboratory.

Ma, O., N. Alkadi, P. Cappers, P. Denholm, J. Dudley, S. Goli, M. Hummon, S. Kiliccote, J. MacDonald, N. Matson, D. Olsen, C. Rose, M. D. Sohn, M. Starke, B. Kirby, and M. O'Malley. 2013. "Demand Response for Ancillary Services." IEEE Transactions on Smart Grid 4(4): 1988-995.

MacDonald, A. E., C. T. M. Clack, A. Alexander, A. Dunbar, J. Wilczak, and Y. Xie. 2016. "Future Cost-Competitive Electricity Systems and Their Impact on US CO2 Emissions." Nature Climate Change 6: 526-31. http://dx.doi.org/10.1038/nclimate2921

Mai, T., M. M. Hand, S. F. Baldwin, R. H. Wiser, G. L. Brinkman, P. Denholm, D. J. Arent, G. Porro, D. Sandor, D. J. Hostick, M. Milligan, E. A. DeMeo, and M. Bazilian. 2014. "Renewable Electricity Futures for the United States." IEEE Transactions on Sustainable Energy 5 372-8. http://dx.doi.org/10.1109/TSTE.2013.2290472

Mills, A., and R. Wiser. 2012. Changes in the Economic Value of Variable Generation at High Penetration Levels: A Pilot Case Study of California. LBNL-5445E. Berkeley, CA: Ernest Orlando Lawrence Berkeley National Laboratory. http://emp.lbl.gov/sites/all/files/lbnl5445e.pdf.

. 2010. Implications of Wide-Area Geographic Diversity for Short-Term Variability of Solar Power. LBNL-3884E. Berkeley, CA: Lawrence Berkeley National Laboratory. doi: $10.2172 / 986925$

NREL (National Renewable Energy Laboratory). 2016. "System Advisor Model Version 2016.3.14 (SAM 2016.3.14).” Accessed September 8, 2017: https://sam.nrel.gov/content/downloads.

Newell, Samuel A., Kathleen Spees, Johannes P. Pfeifenberger, Ioanna Karkatsouli, Nick Wintermantel, and Kevin Carden. 2014. "Estimating the Economically Optimal Reserve Margin in ERCOT." Cambridge, MA: Brattle Group. http://www.brattle.com/system/news/pdfs/000/000/613/original/Estimating the Economically Optimal_Reserve_Margin_in_ERCOT.pdf?1391445083. 
Nykvist, B., and M. Nilsson. 2015. "Rapidly Falling Costs of Battery Packs for Electric Vehicles." Nature Climate Change 5: 329-32.

Perez, R., M. Taylor, T. Hoff, and J.P. Ross. 2008. "Reaching Consensus in the Definition of Photovoltaics Capacity Credit in the USA: A Practical Application of Satellite-Derived Solar Resource Data." IEEE Journal of Selected Topics in Applied Earth Observations and Remote Sensing 1(1): 28-33. http://dx.doi.org/10.1109/JSTARS.2008.2004362

Peterson, S. B., J. Apt, and J. F. Whitacre. 2010. "Lithium-Ion Battery Cell Degradation Resulting from Realistic Vehicle and Vehicle-to-Grid Utilization." Journal of Power Sources 195: 2385-92.

Potomac Economics. 2017. 2016 State of the Market Report for the ERCOT Wholesale Electricity Markets. Fairfax, VA: Potomac Economics. https://www.potomaceconomics.com/wpcontent/uploads/2017/06/2016-ERCOT-State-of-the-Market-Report.pdf.

Sioshansi, R., S.H. Madaeni, and P. Denholm. 2014. "A Dynamic Programming Approach to Estimate the Capacity Value of Energy Storage." IEEE Transactions on Power Systems 29(1): 395-403.

Tabone, Michaelangelo D., Christoph Goebel, and Duncan S. Callaway. 2016. "The Effect of PV Siting on Power System Flexibility Needs." Solar Energy 139:776-786 doi:10.1016/j.solener.2016.10.018.

DOE (U.S. Department of Energy). 2017. “DOE Global Energy Storage Database.” Accessed September 8, 2017. http://www.energystorageexchange.org/.

- 2015. Wind Vision: A New Era for Wind Power in the United States. DOE/GO-1020154557. Washington, D.C.: U. S. Department of Energy.

- 2014. “A New Vision for U.S. Hydropower.” Retrieved from http://www.osti.gov/scitech/servlets/purl/1220855.

Xu, B., Y. Dvorkin, D. S. Kirschen, C. A. Silva-Monroy, and J. Watson. 2016. "A Comparison of Policies on the Participation of Storage in U.S. Frequency Regulation Markets." 2016 IEEE Power and Energy Society General Meeting (PESGM), pp. 1-5. DOI: 10.1109/PESGM.2016.7741531

Zhou, A., T. Levin, and G. Conzelmann. 2016. Survey of U.S. Ancillary Services Markets. ANL/ESD-16/1. Argonne, IL: Argonne National Laboratory. http://www.ipd.anl.gov/anlpubs/2016/01/124217.pdf. 


\section{Appendix}

Figure A-1 summarizes the price load data used in the REFlex model. It was used to determine the marginal energy value of wind to site each wind cluster.

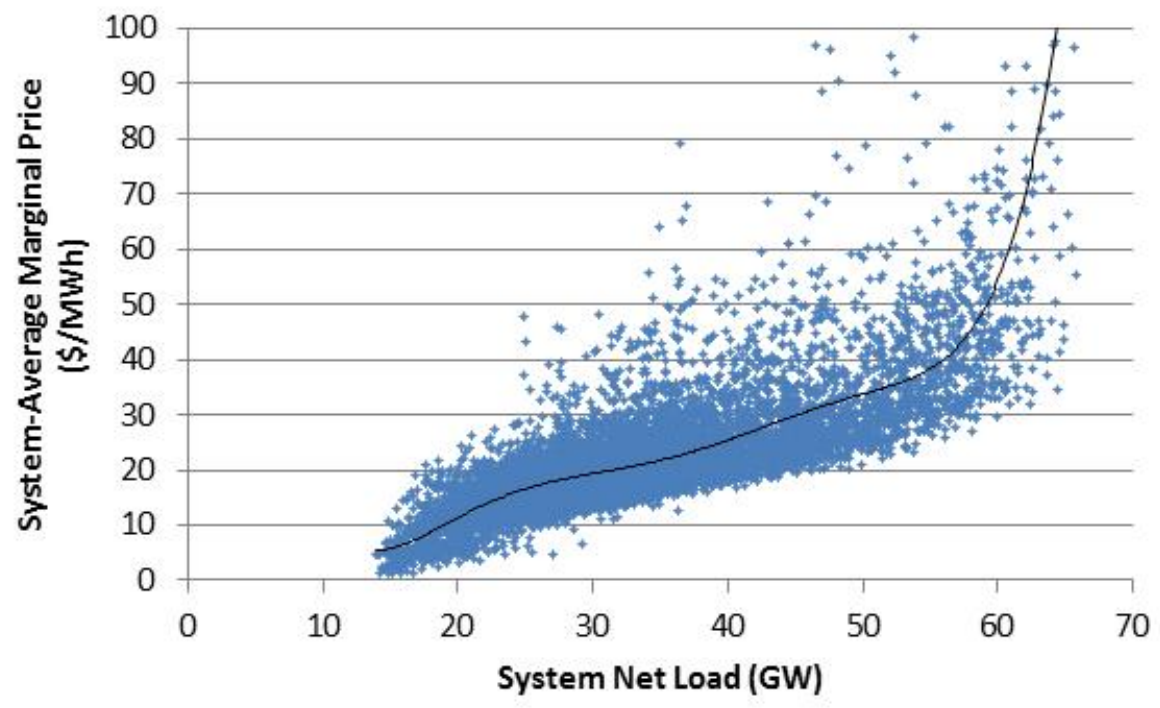

Figure A-1. Price and net load relationship in ERCOT in 2016

Figure A-2 provides the variation in curtailment across all six years of data in the Wind Vision mix scenario, without storage. The figures use identical data, but Figure A-2 (a) zooms in to the penetration values above $52 \%$ to show the yearly difference.

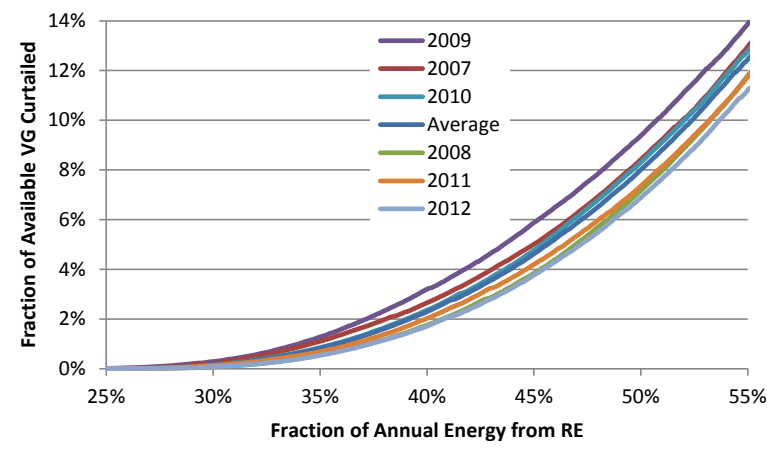

a) Full Range

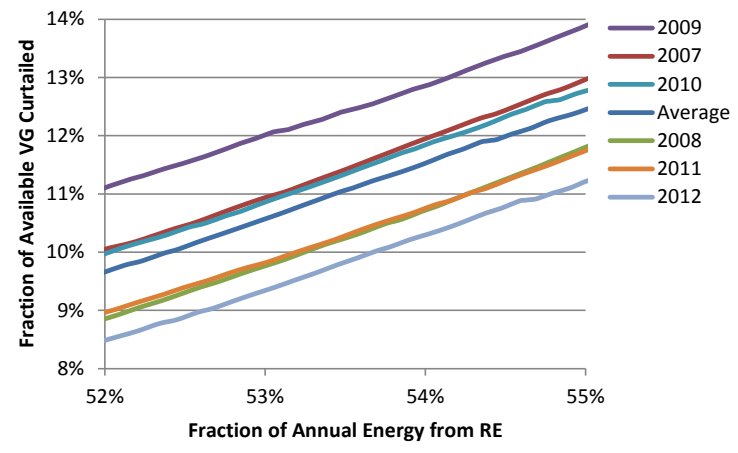

b) At highest penetration levels

Figure A-2. Variation in Curtailment by Year 